\title{
Asymmetric Conjugate Addition for the Preparation of syn-1,3-Dimethyl Arrays: \\ Synthesis and Structure Elucidation of Capensifuranone
}

David R. Williams, * Andrea L. Nold, and Richard J. Mullins

Department of Chemistry

Indiana University

Bloomington, IN 47405

\section{Supporting Information}

General Experimental Detail $\quad$ S2

${ }^{1} \mathrm{H}$ NMR for compound 12

${ }^{13} \mathrm{C}$ NMR for compound 12

${ }^{1} \mathrm{H}$ NMR for compound (3S)-3-methylhexanol S5

${ }^{13} \mathrm{C}$ NMR for compound (3S)-3-methylhexanol S6

${ }^{1} \mathrm{H}$ NMR for compound $13 \quad$ S7

${ }^{13} \mathrm{C}$ NMR for compound 13

${ }^{1} \mathrm{H}$ NMR for compound $14 \quad$ S9

${ }^{13} \mathrm{C}$ NMR for compound $14 \quad \mathrm{~S} 10$

${ }^{1} \mathrm{H}$ NMR for compound 15

${ }^{13} \mathrm{C}$ NMR for compound $15 \quad \mathrm{~S} 12$

${ }^{1} \mathrm{H}$ NMR for compound $16 \quad \mathrm{~S} 13$

${ }^{13} \mathrm{C}$ NMR for compound $16 \quad \mathrm{~S} 14$

${ }^{1} \mathrm{H}$ NMR for compound $17 \quad \mathrm{~S} 15$

${ }^{13} \mathrm{C}$ NMR for compound $17 \quad \mathrm{~S} 16$

${ }^{1} \mathrm{H}$ NMR for compound $18 \quad \mathrm{~S} 17$

${ }^{13} \mathrm{C}$ NMR for compound $18 \quad \mathrm{~S} 18$

${ }^{1} \mathrm{H}$ NMR for compound $19 \quad \mathrm{~S} 19$

${ }^{13} \mathrm{C}$ NMR for compound $19 \quad \mathrm{~S} 20$

${ }^{1} \mathrm{H}$ NMR for compound $20 \quad$ S21

${ }^{13} \mathrm{C}$ NMR for compound $20 \quad \mathrm{~S} 22$

${ }^{1} \mathrm{H}$ NMR for compound $22 \quad \mathrm{~S} 23$

${ }^{13} \mathrm{C}$ NMR for compound $22 \quad \mathrm{~S} 24$

${ }^{1} \mathrm{H}$ NMR for compound $23 \quad \$ 25$

${ }^{13}$ C NMR for compound $23 \quad$ S26

${ }^{1} \mathrm{H}$ NMR for compound $24 \quad$ S27

${ }^{13} \mathrm{C}$ NMR for compound $24 \quad \mathrm{~S} 28$

${ }^{1} \mathrm{H}$ NMR for compound $25 \quad \mathrm{~S} 29$

${ }^{13} \mathrm{C}$ NMR for compound 25

${ }^{1} \mathrm{H}$ NMR for compound 27 (epi-capensifuranone) S31

${ }^{13} \mathrm{C}$ NMR for compound 27 (epi-capensifuranone) S32

${ }^{1} \mathrm{H}$ NMR for compound $26 \quad$ S33

${ }^{13} \mathrm{C}$ NMR for compound 26

${ }^{1} \mathrm{H}$ NMR for compound 1 (capensifuranone) $\mathrm{S35}$

${ }^{13}$ C NMR for compound 1 (capensifuranone) S36 


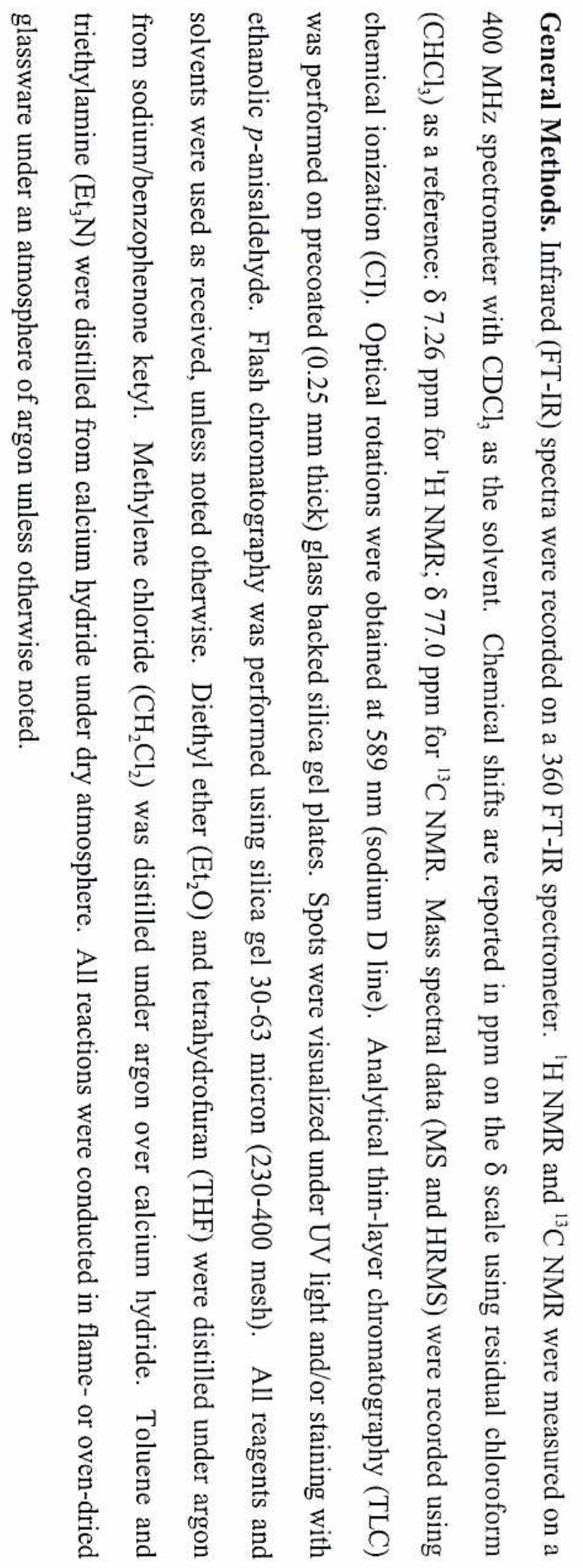




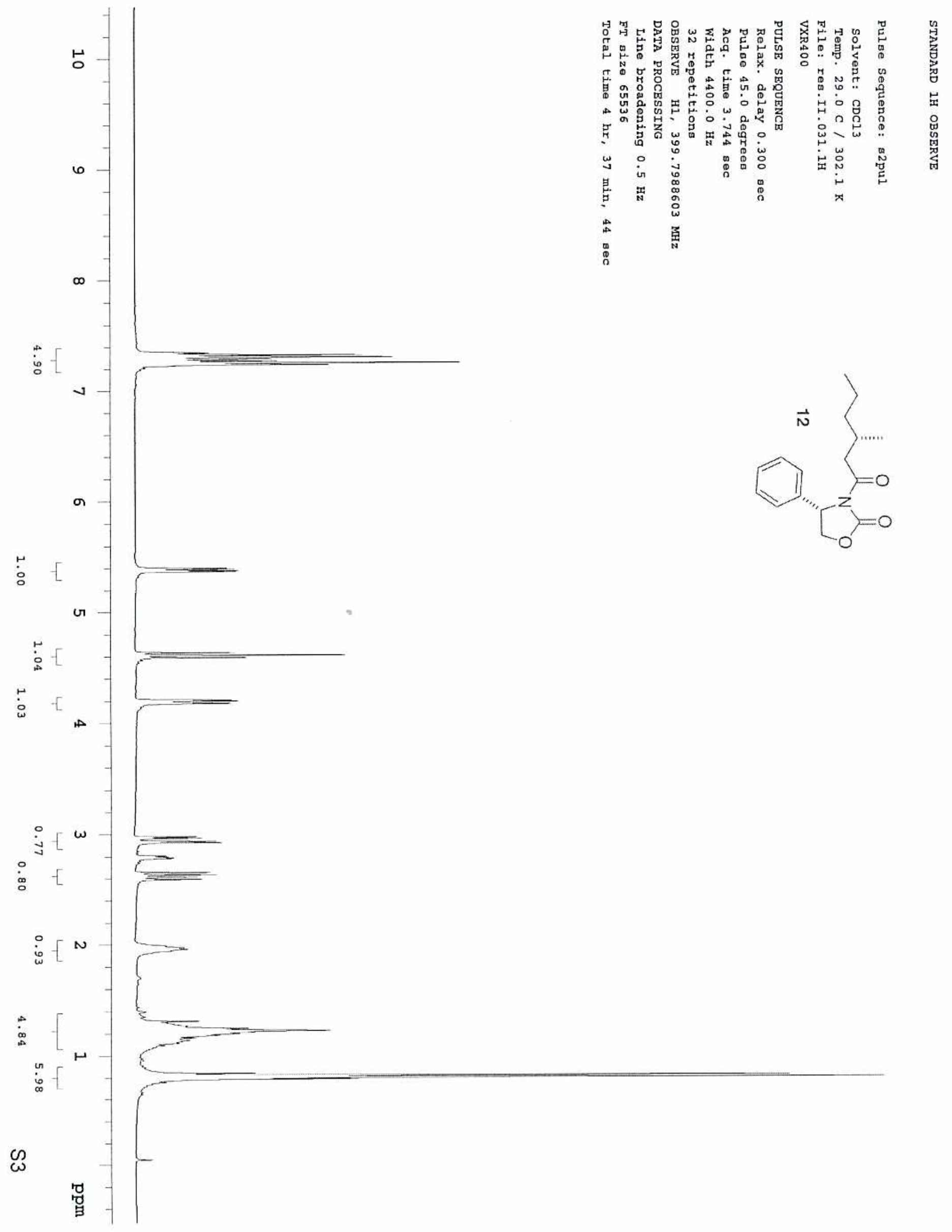




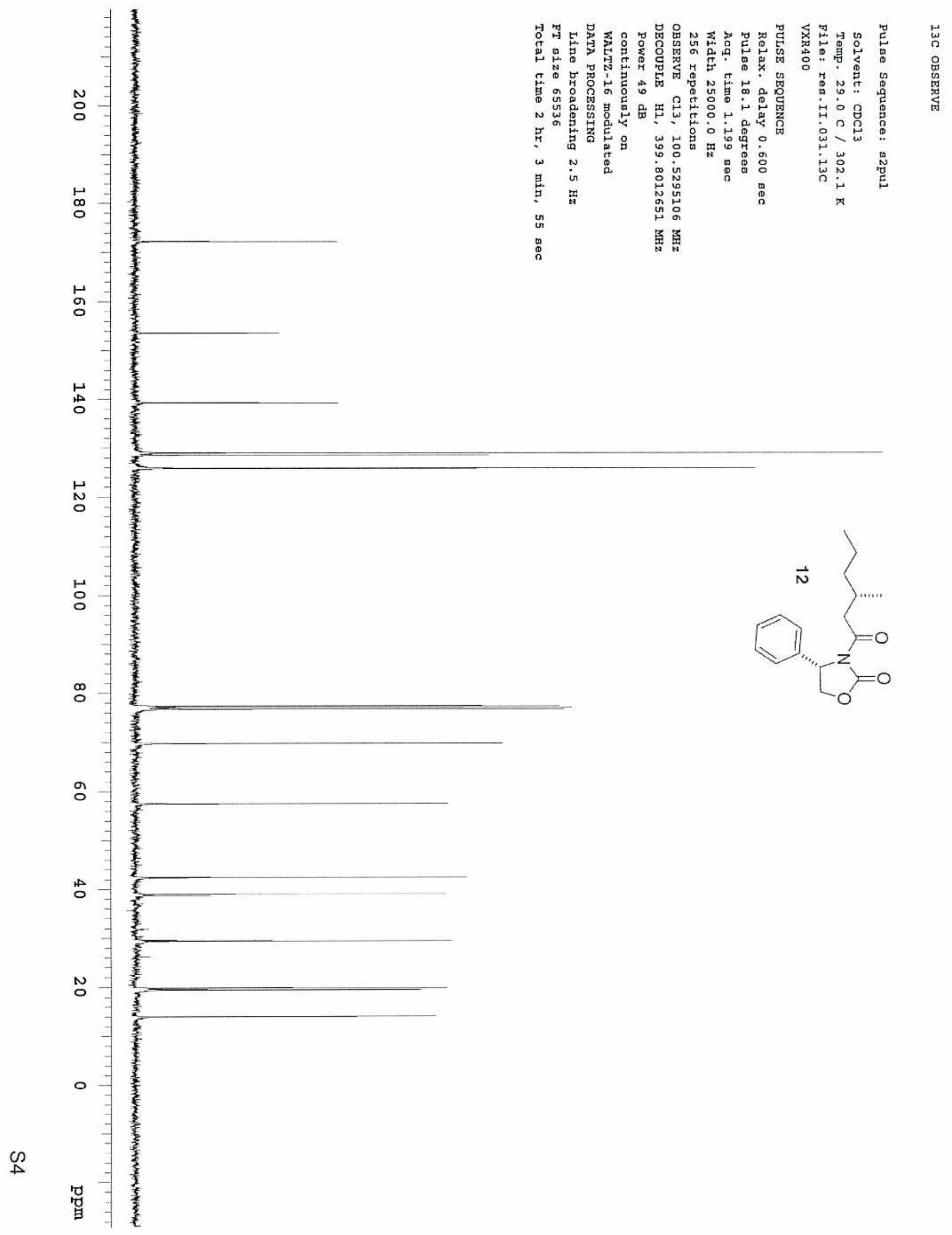




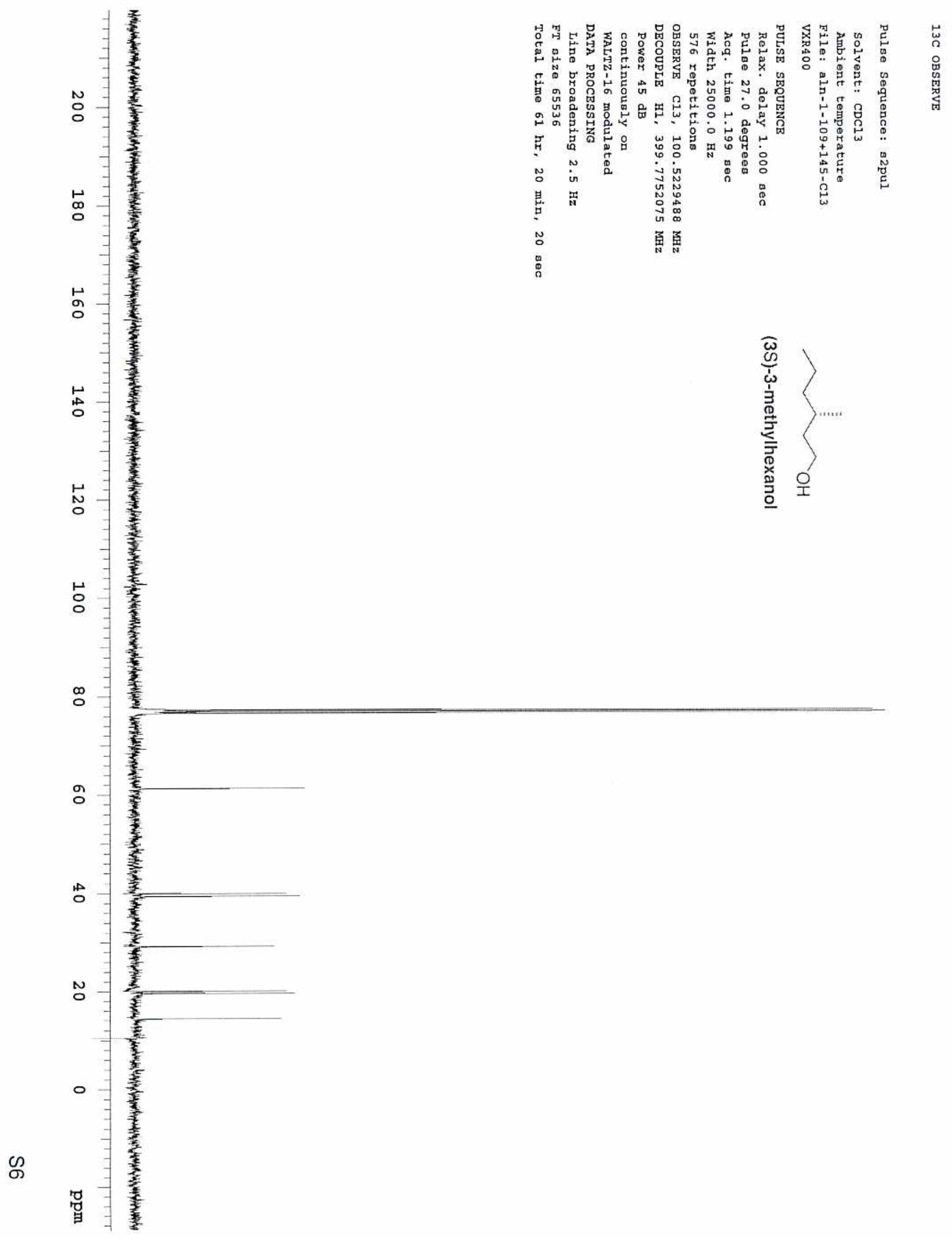




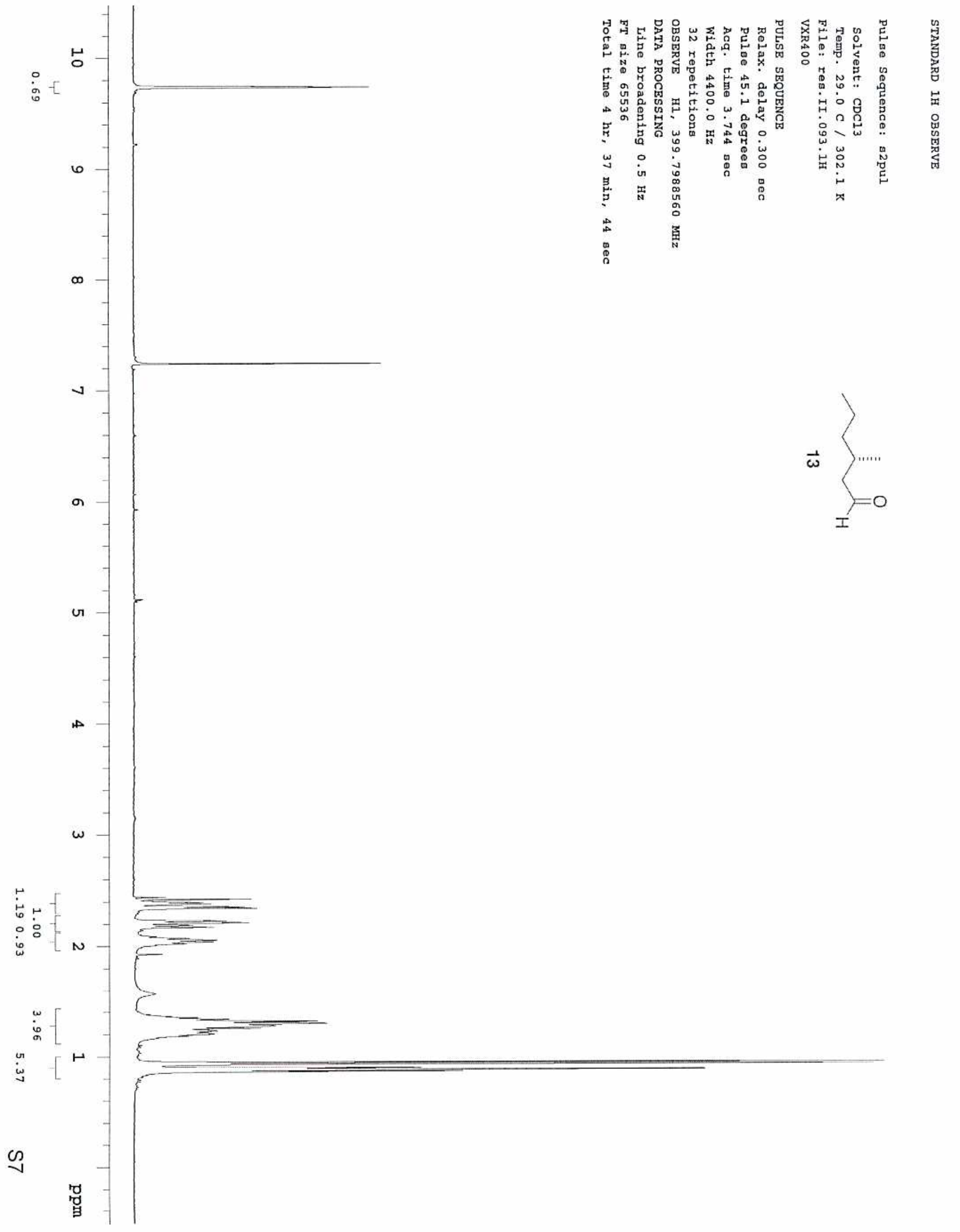




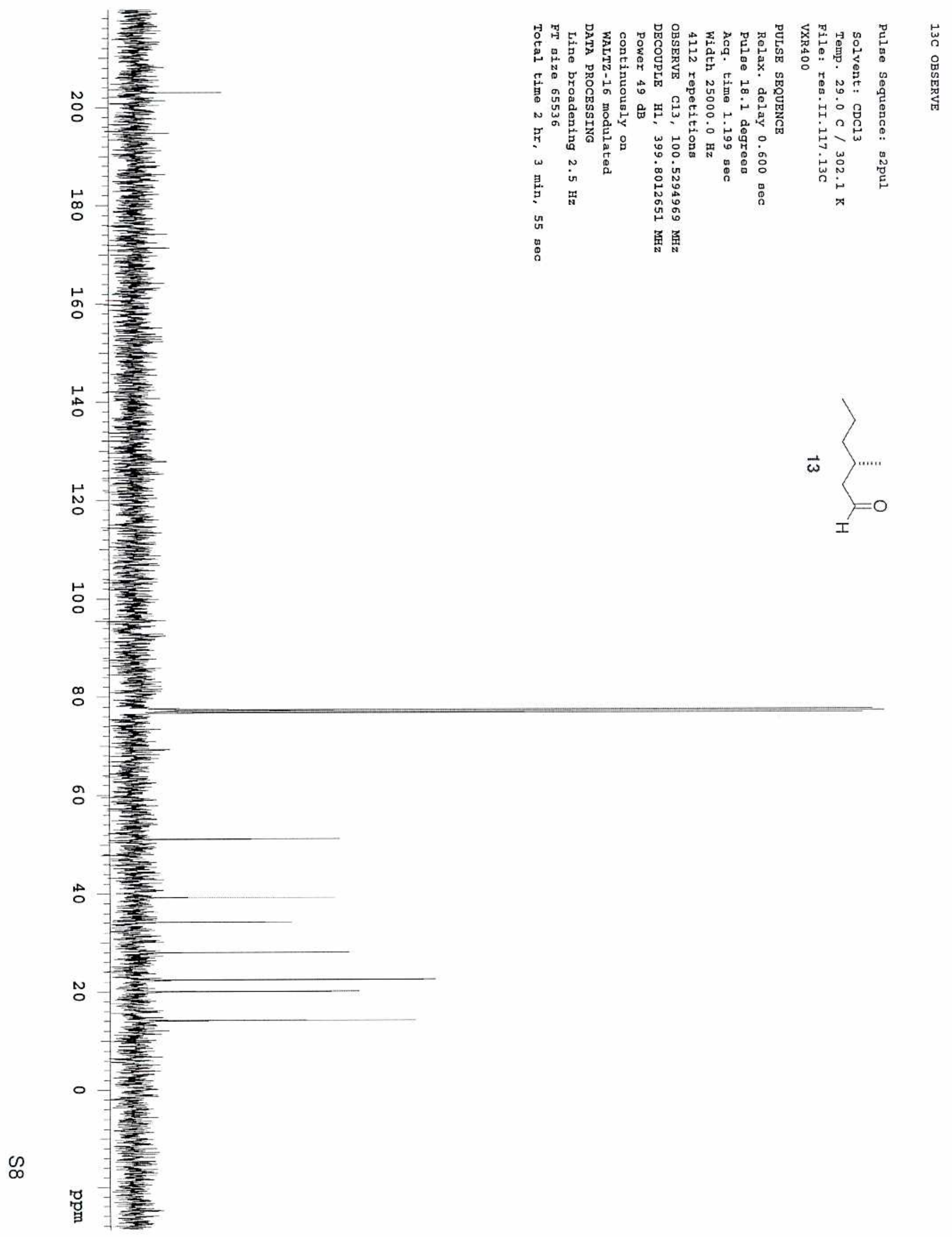




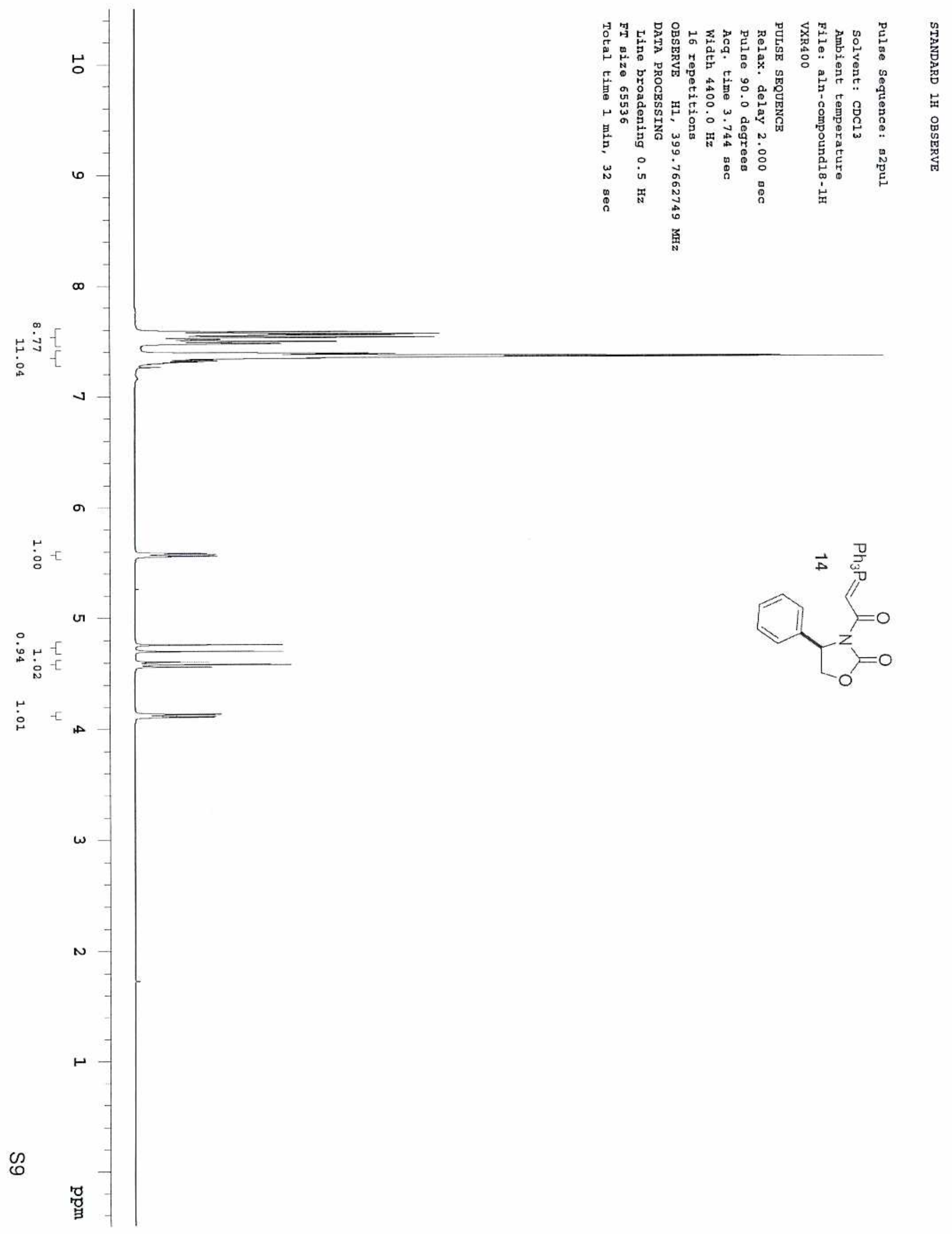




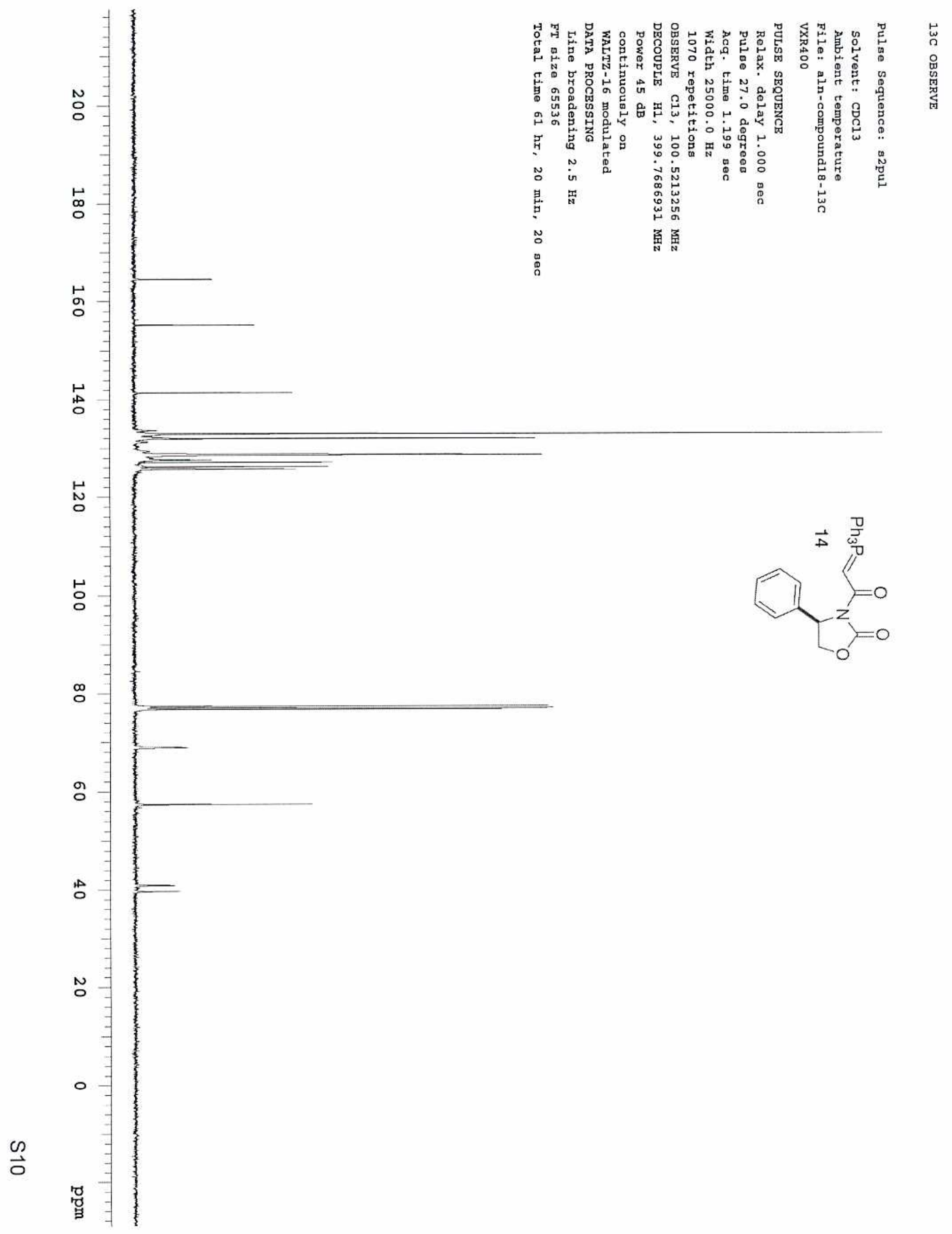




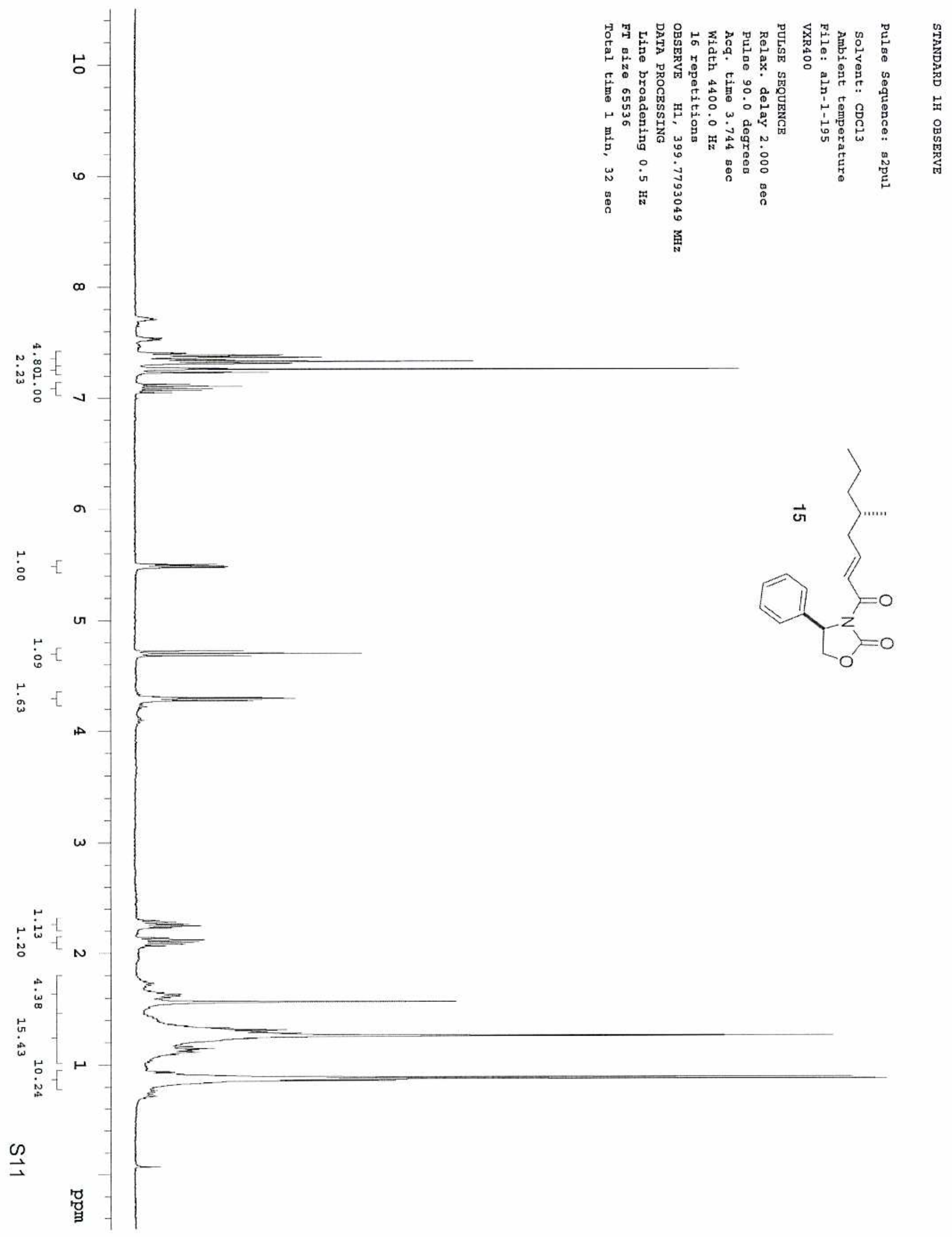




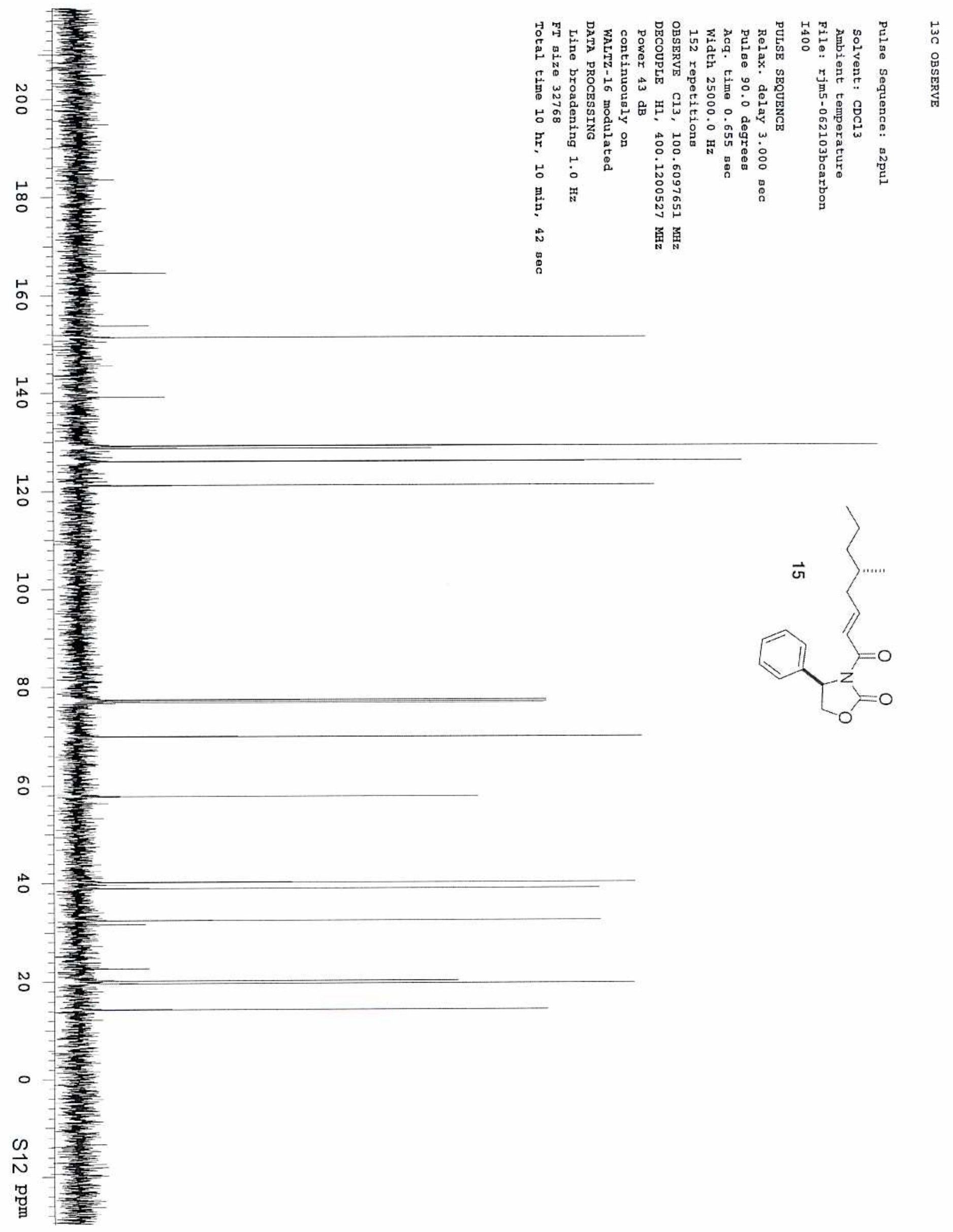




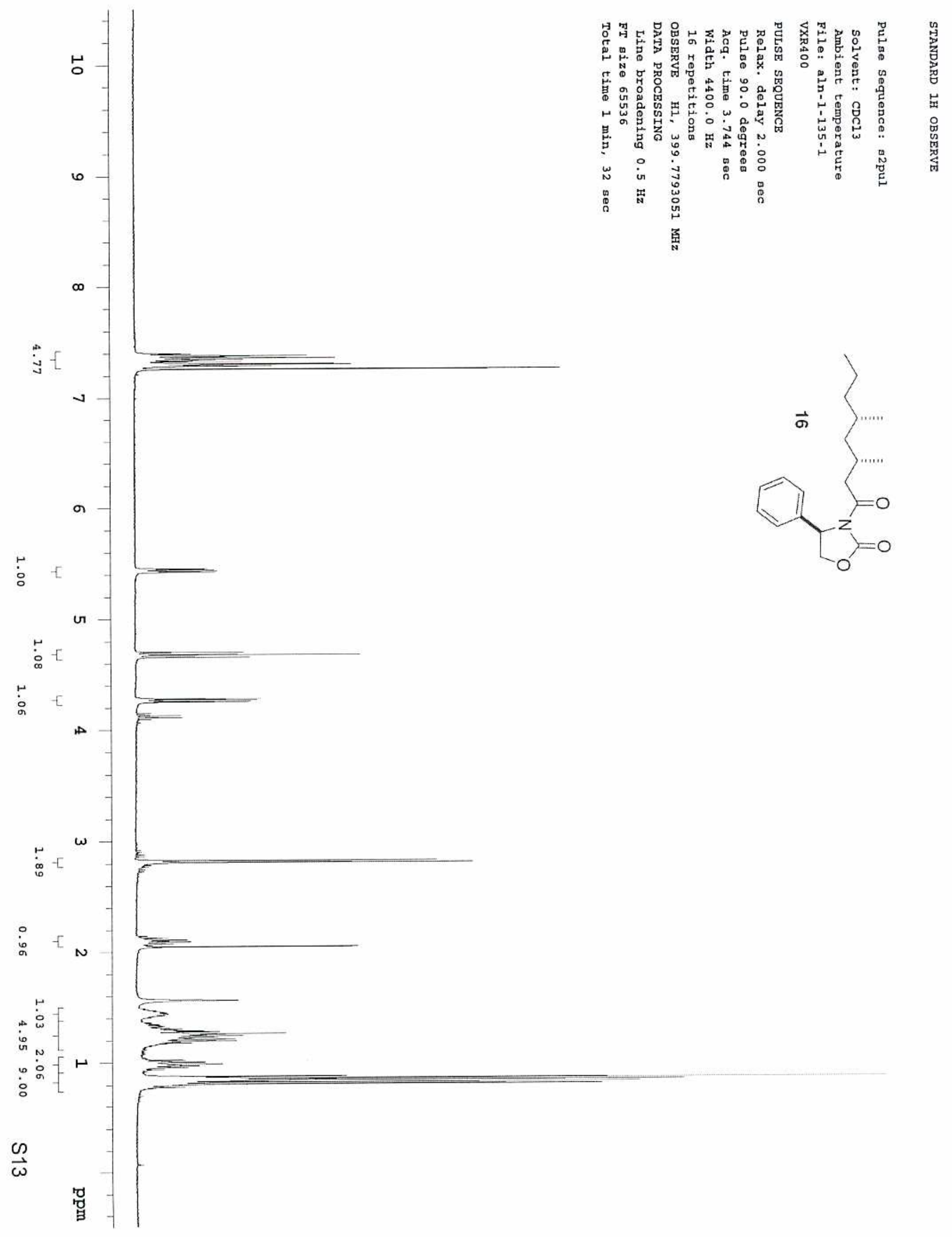




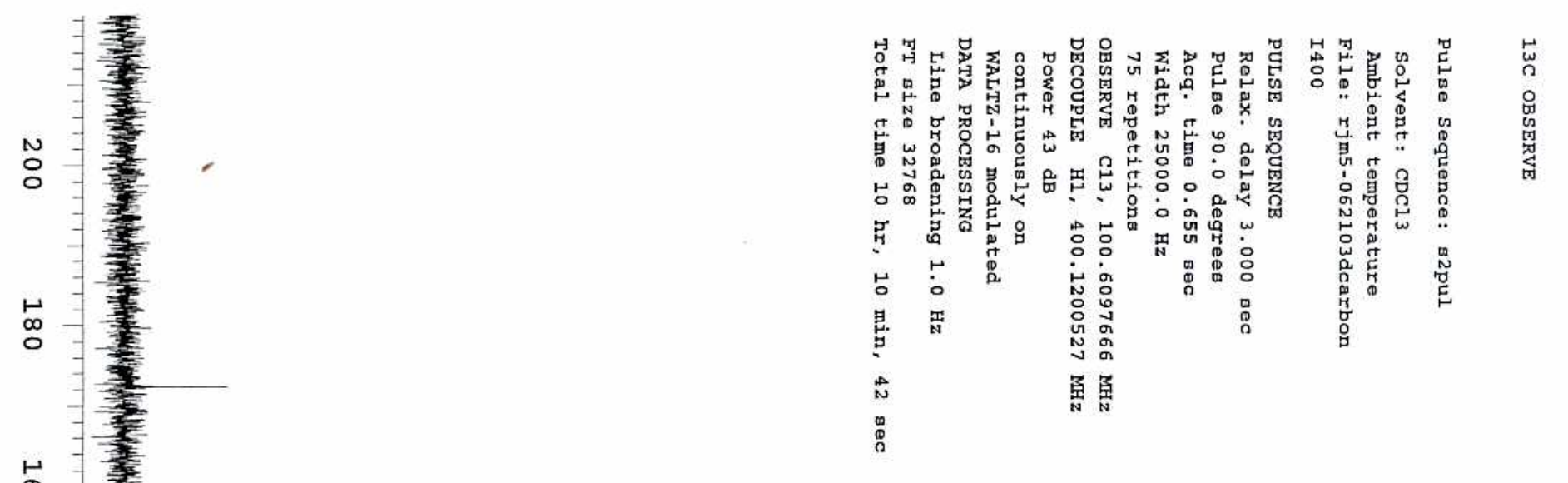




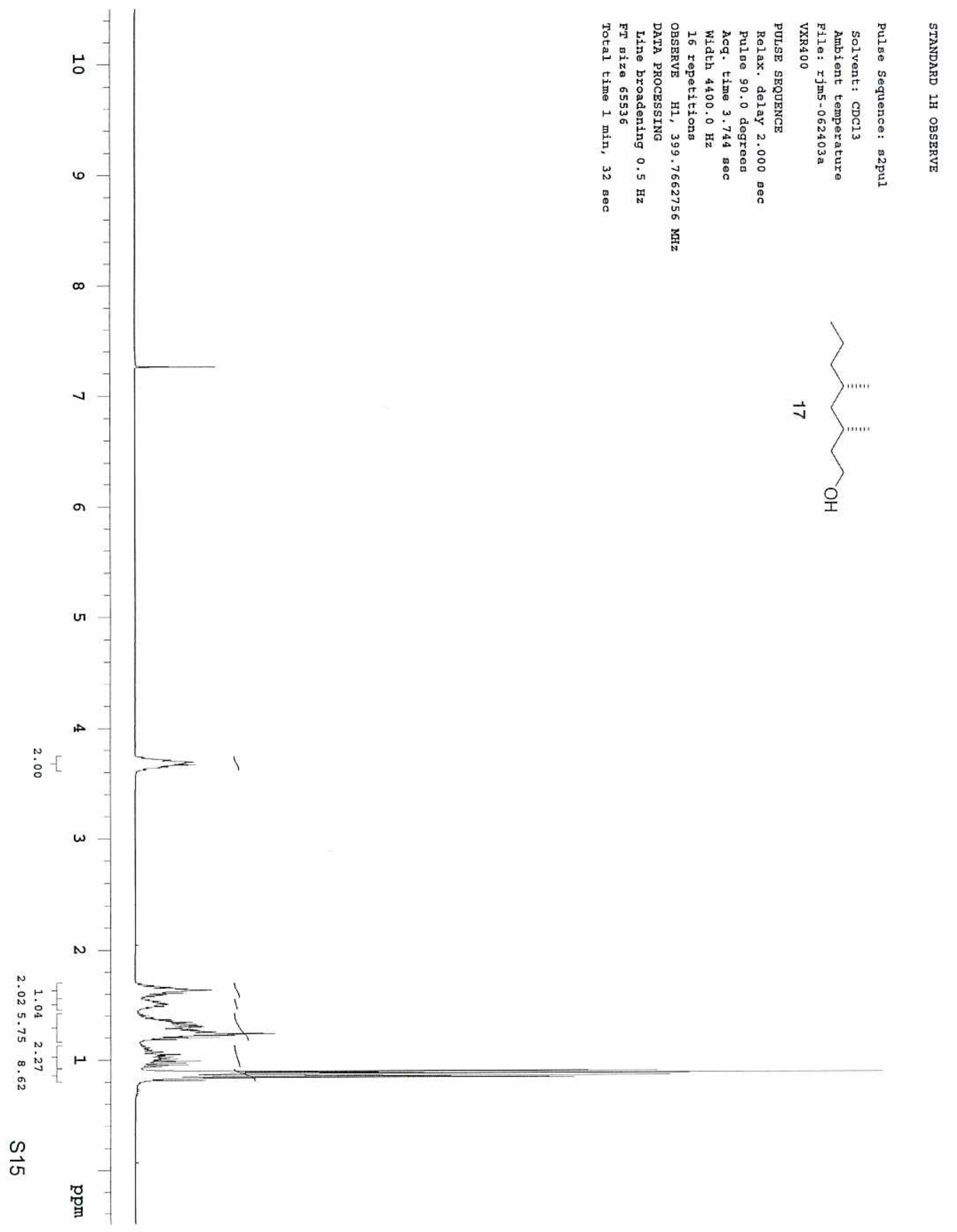




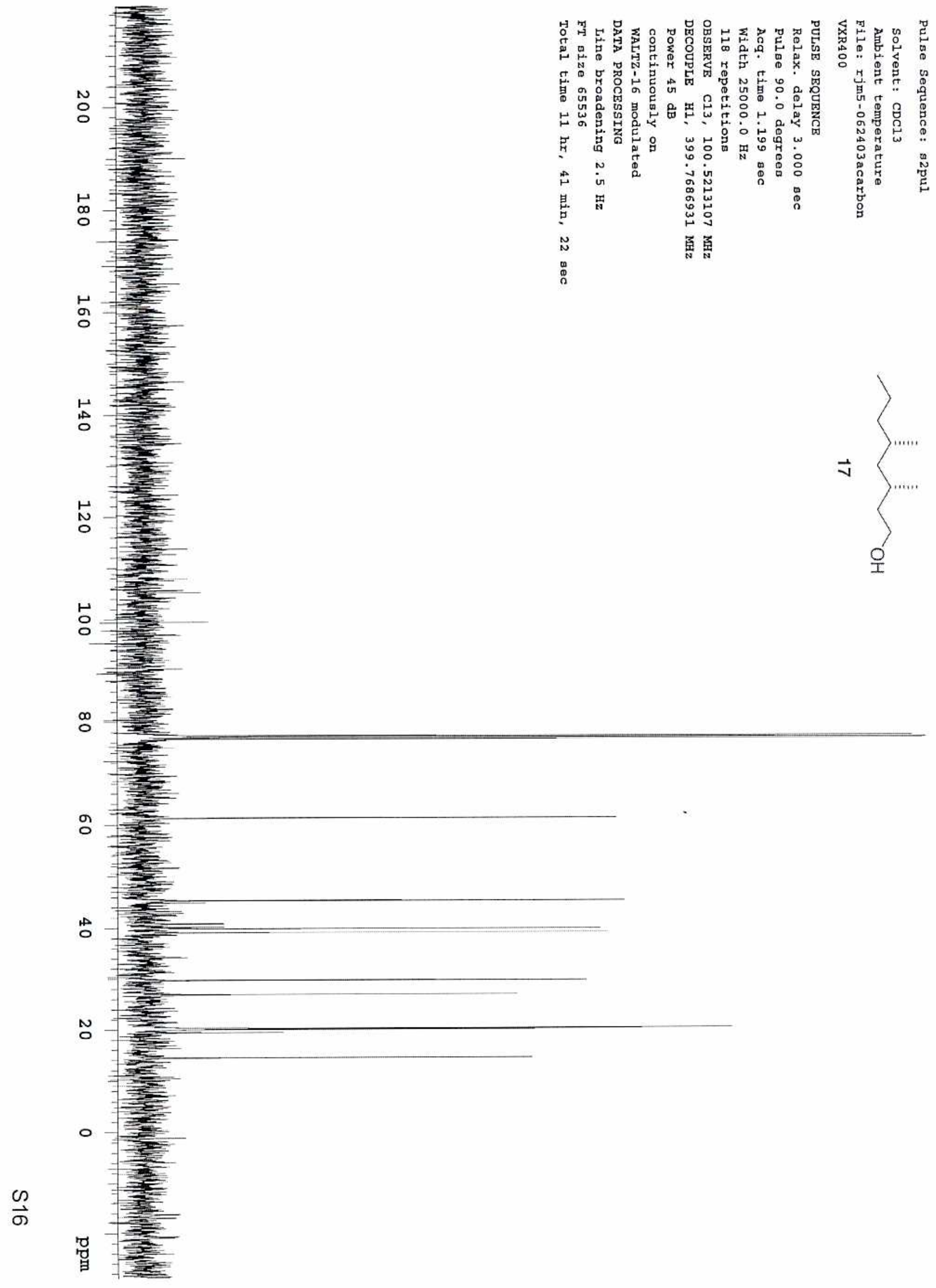




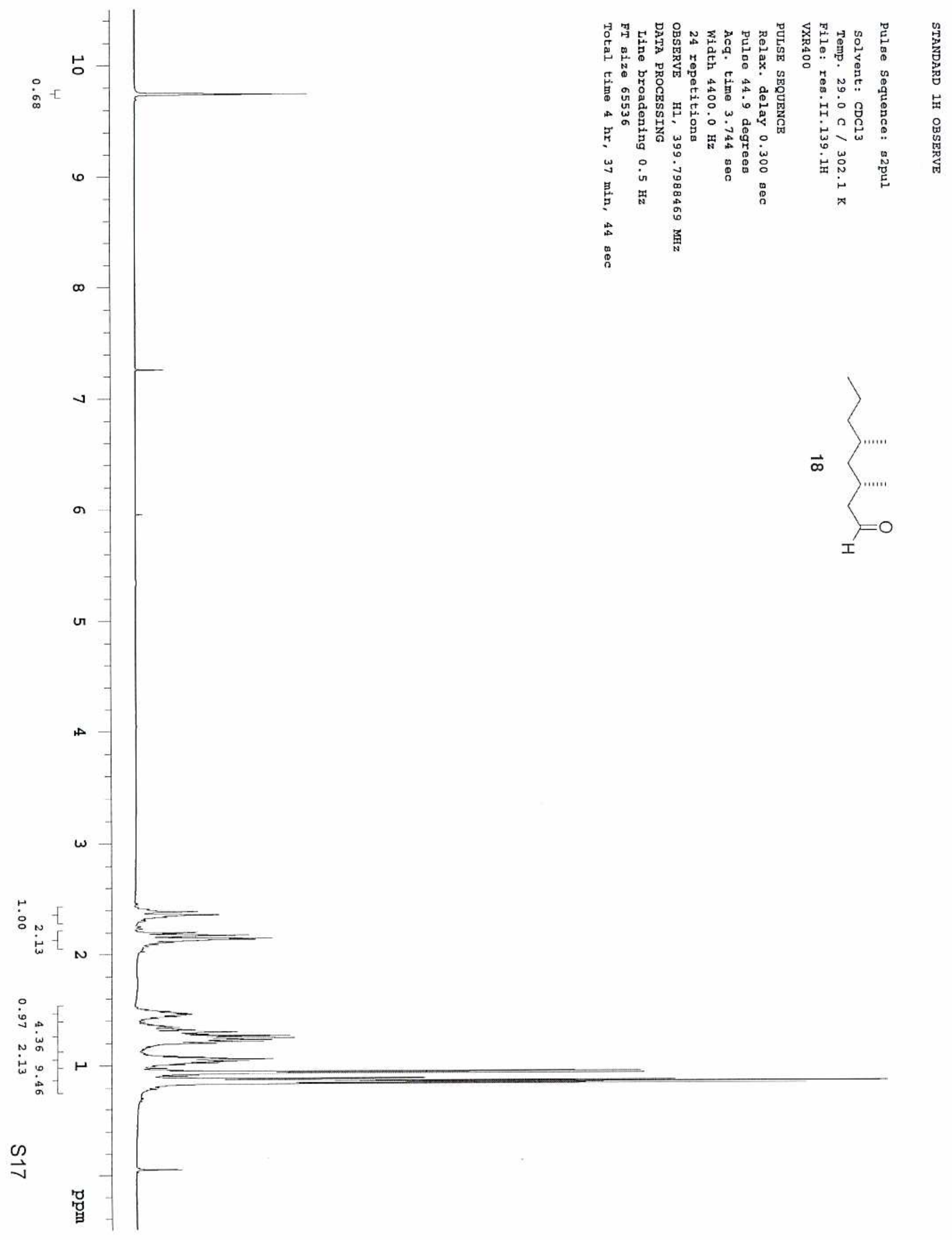




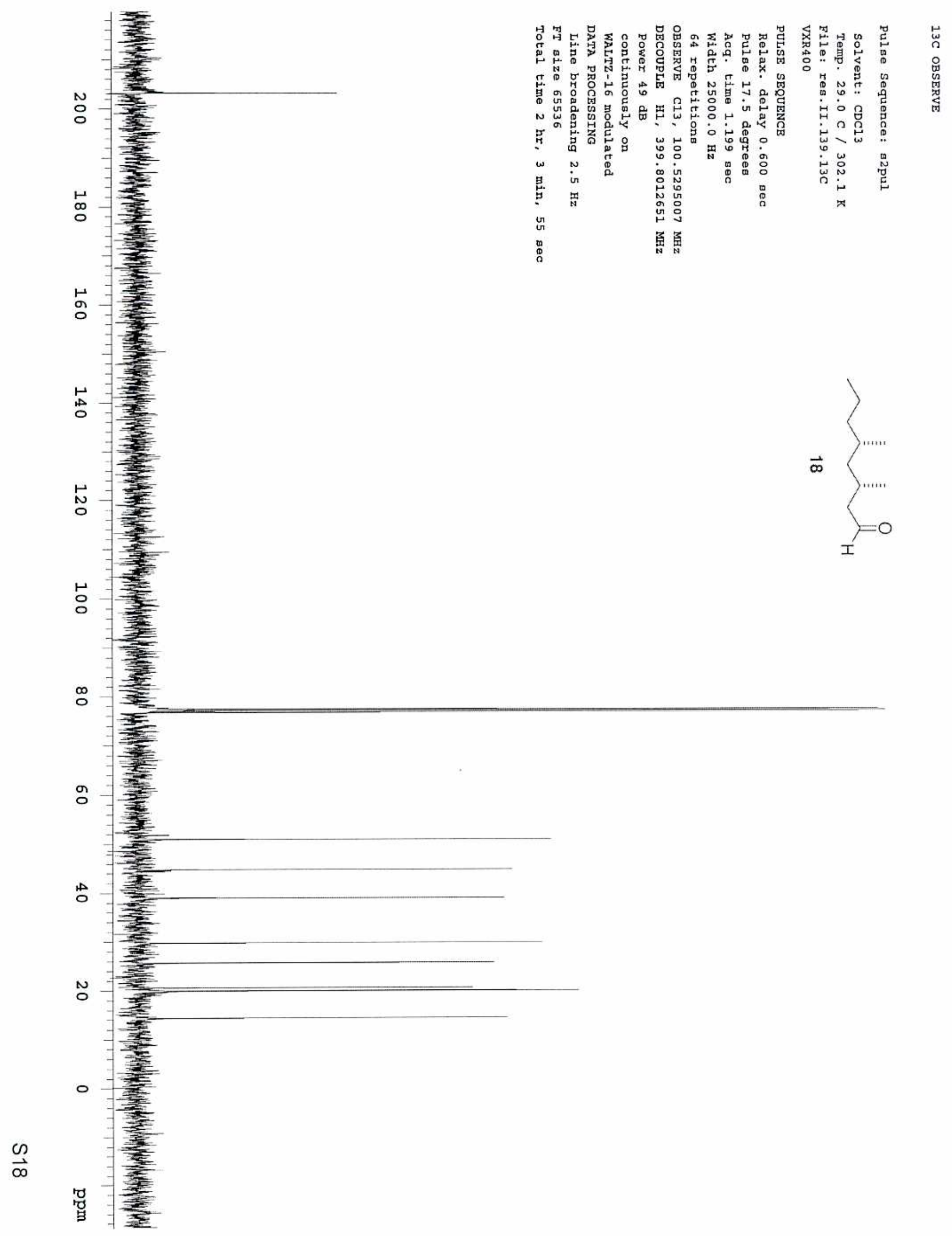




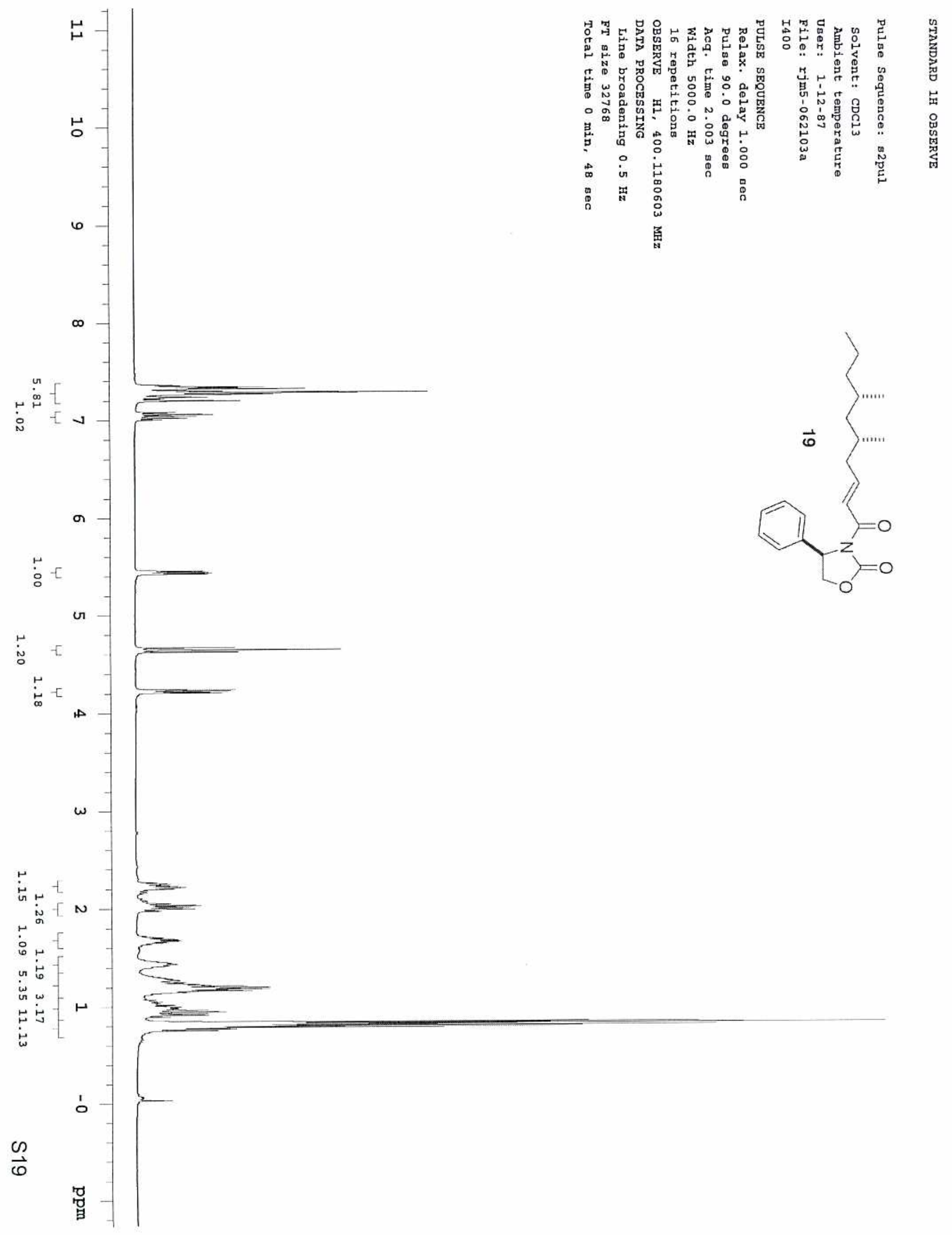




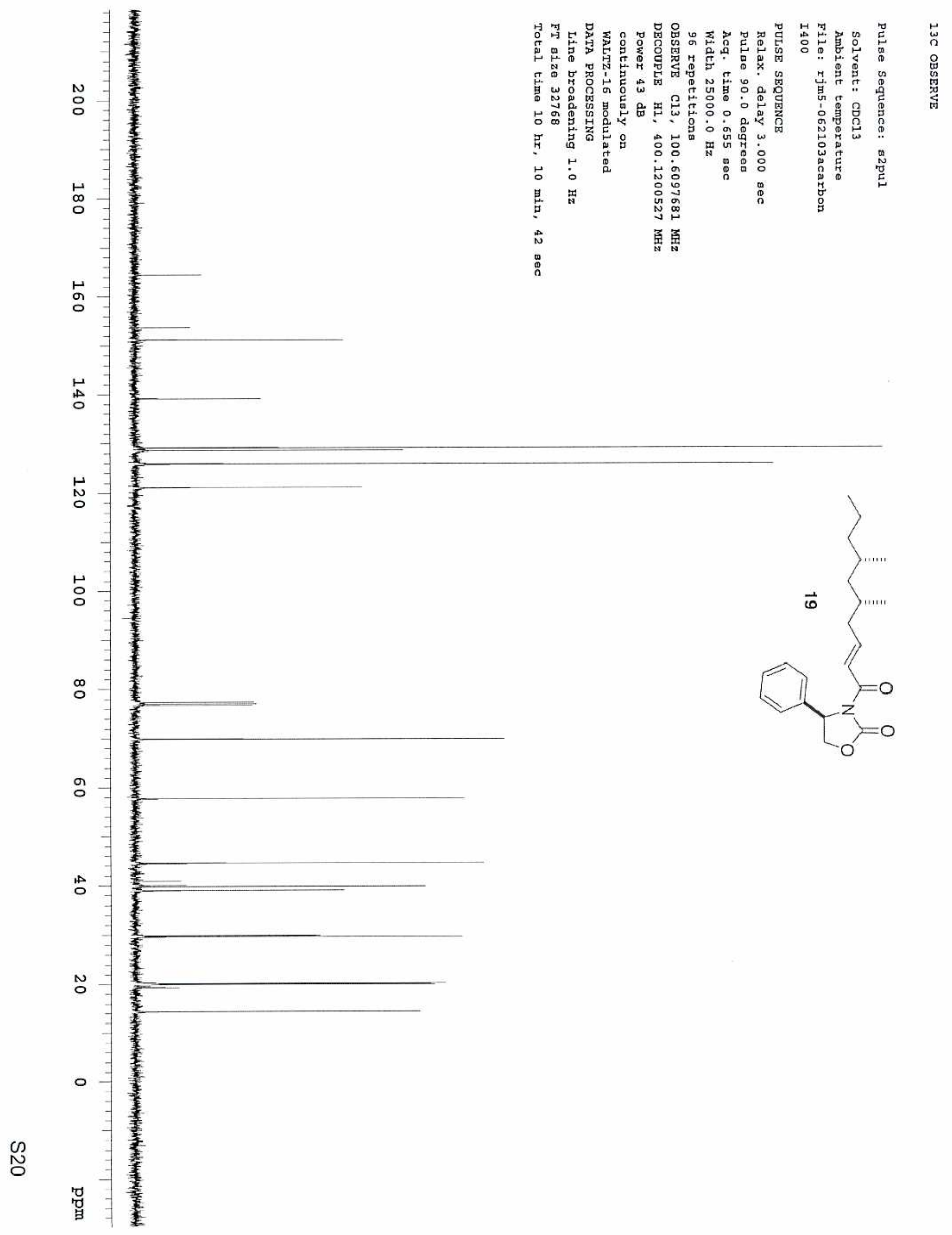




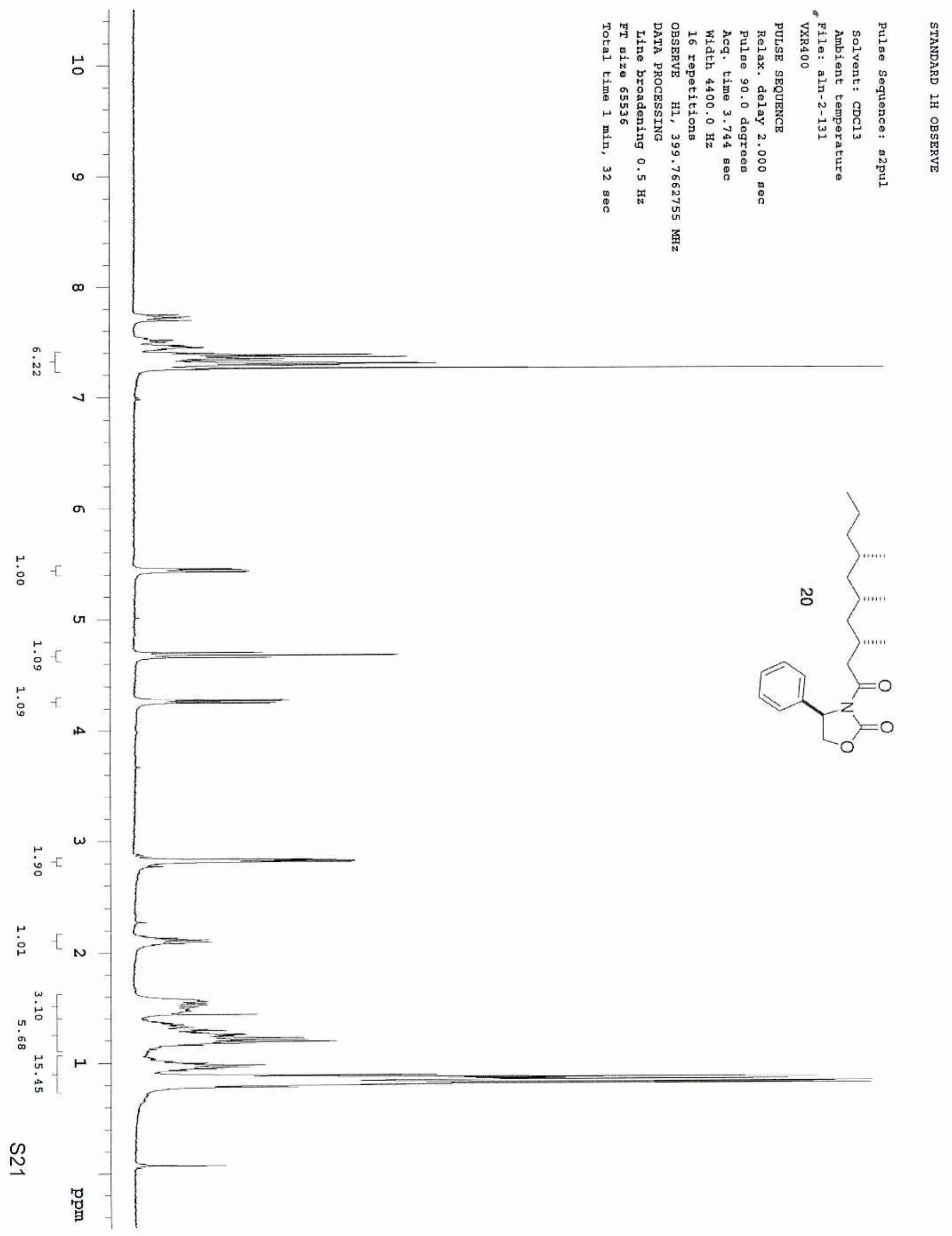




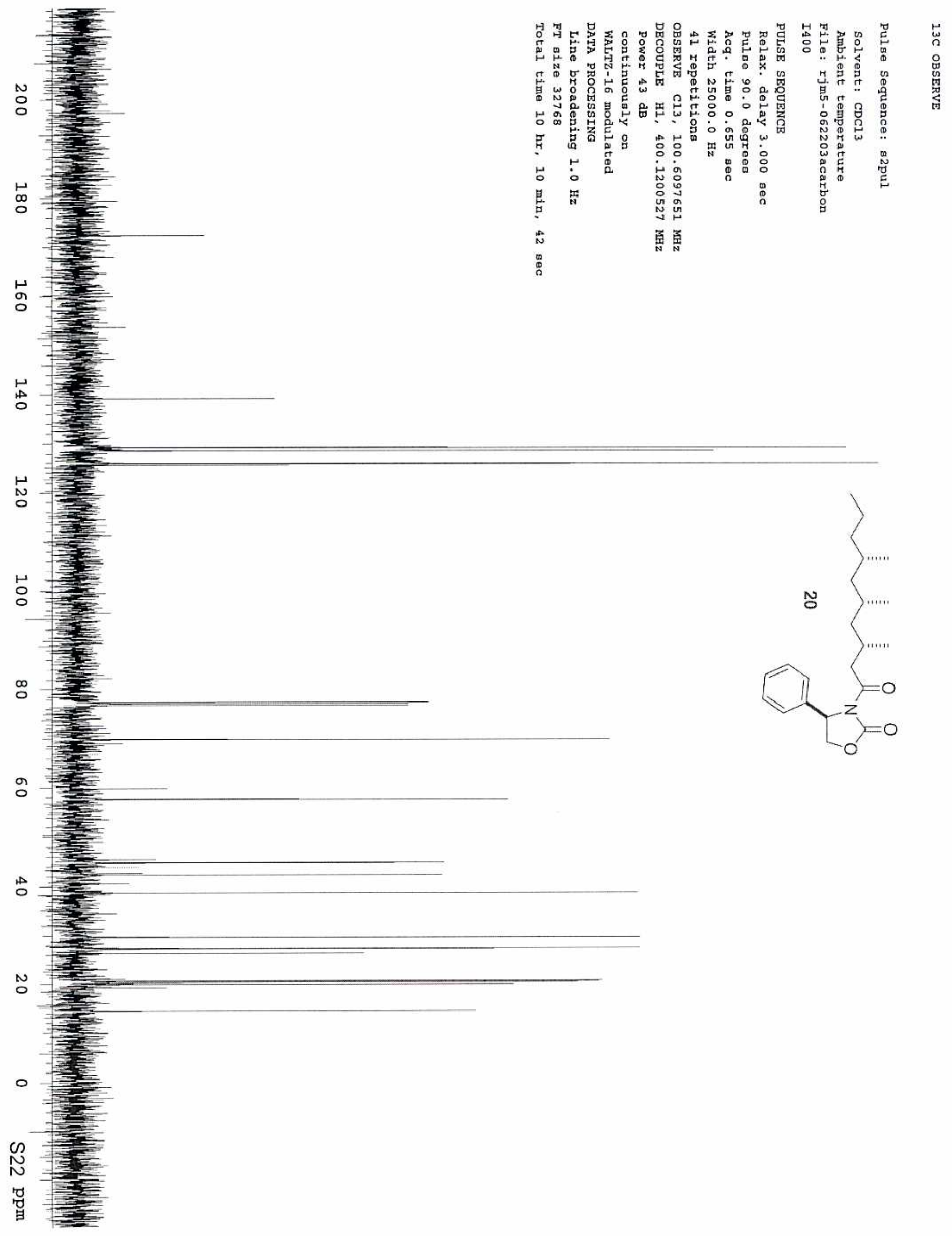




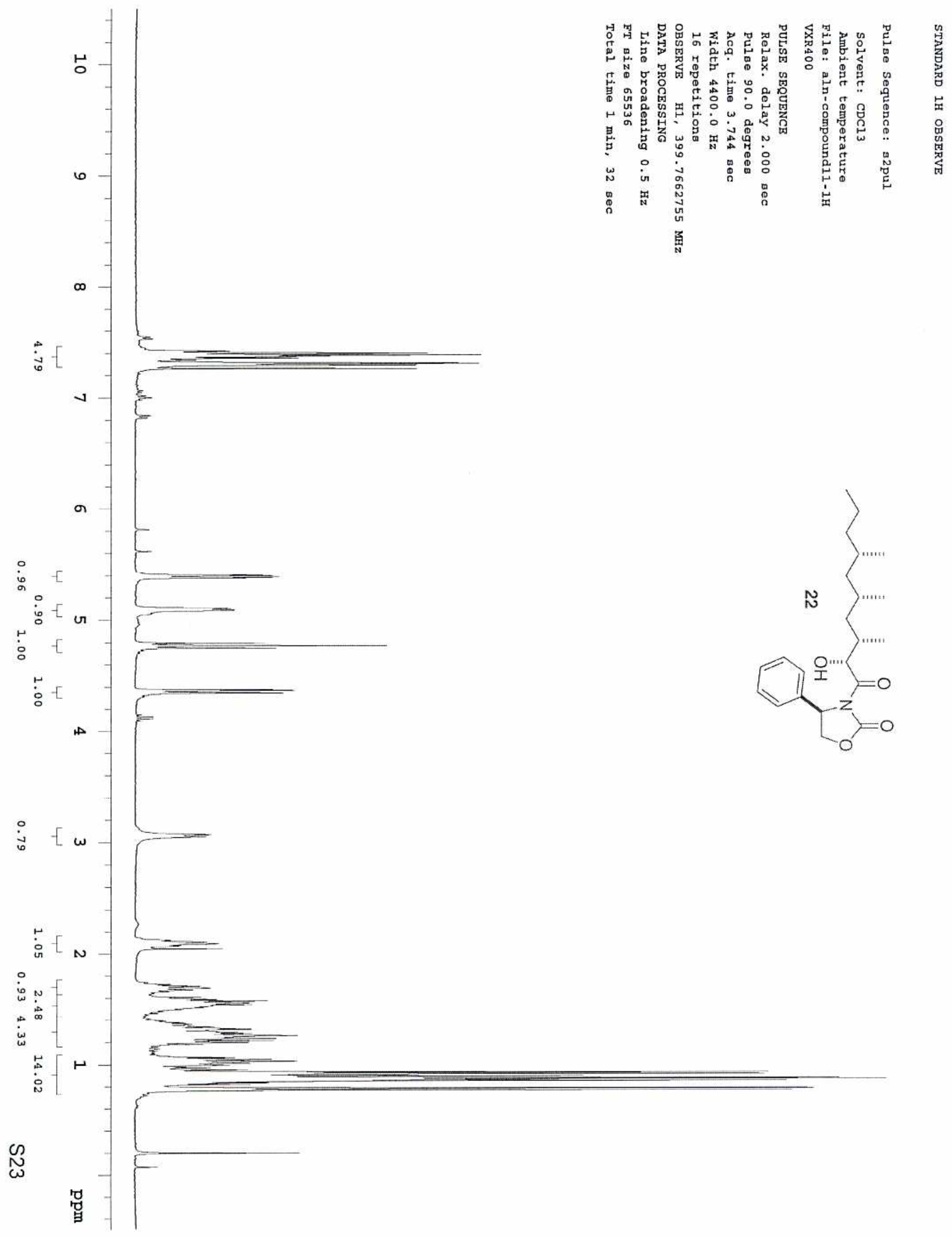




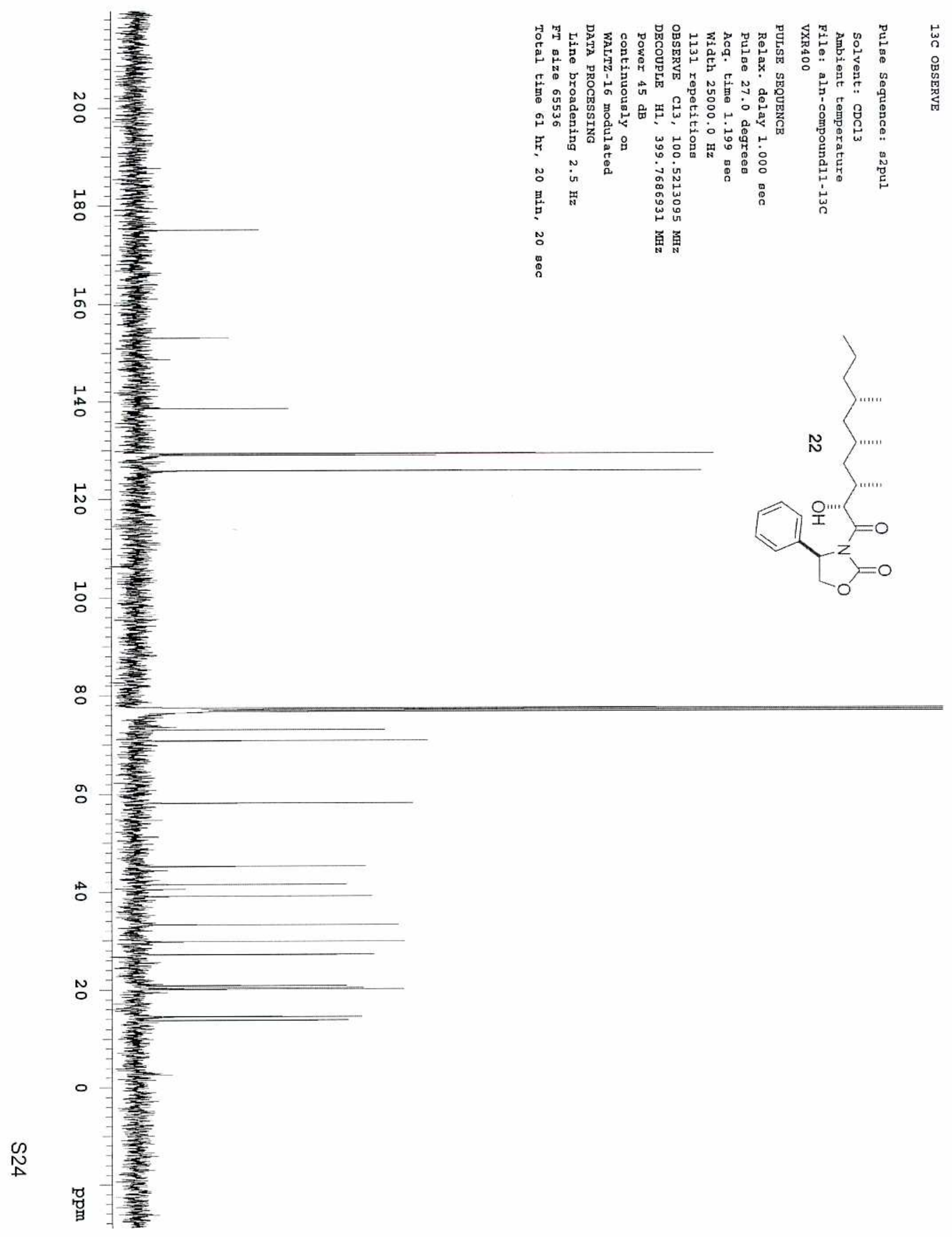




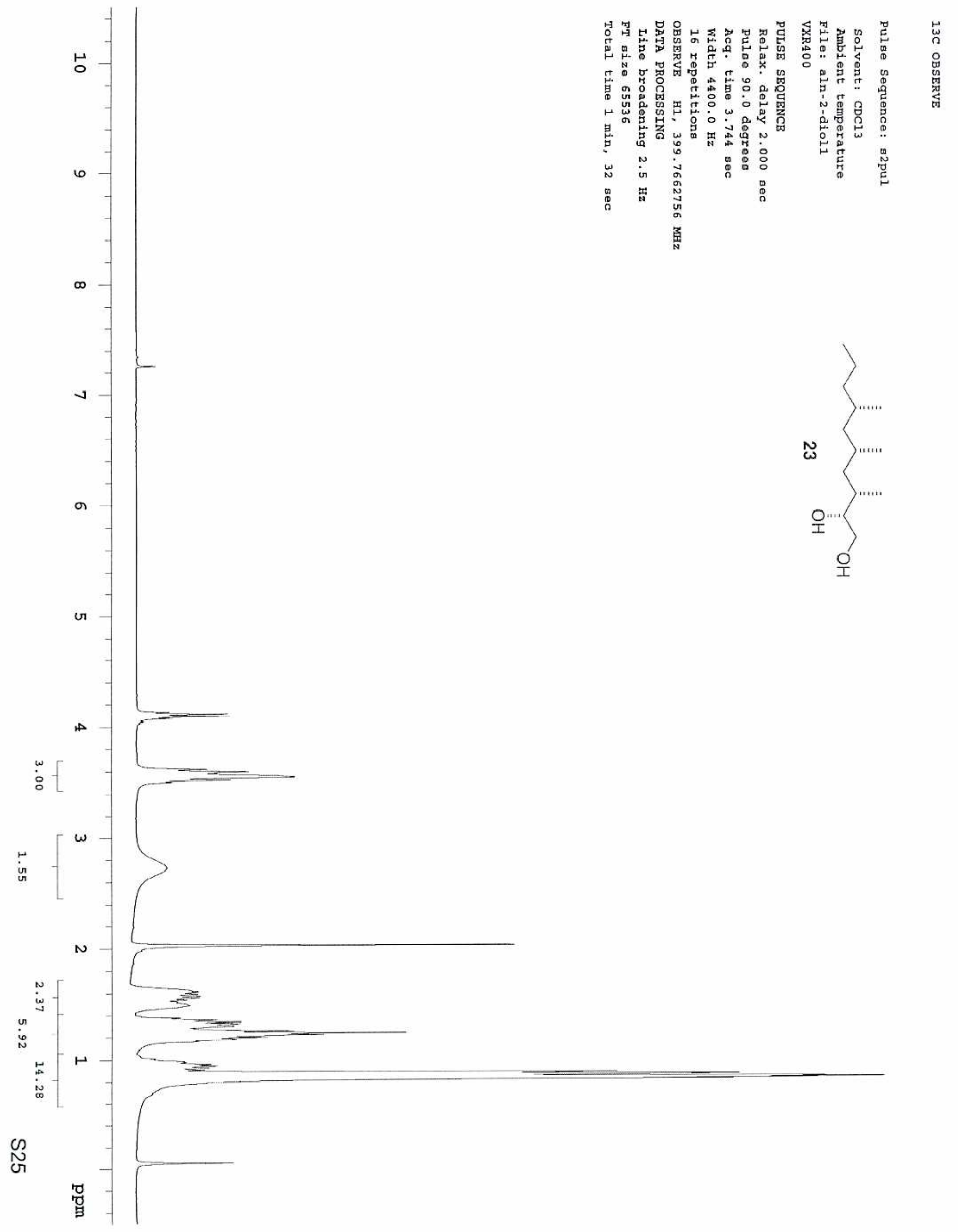




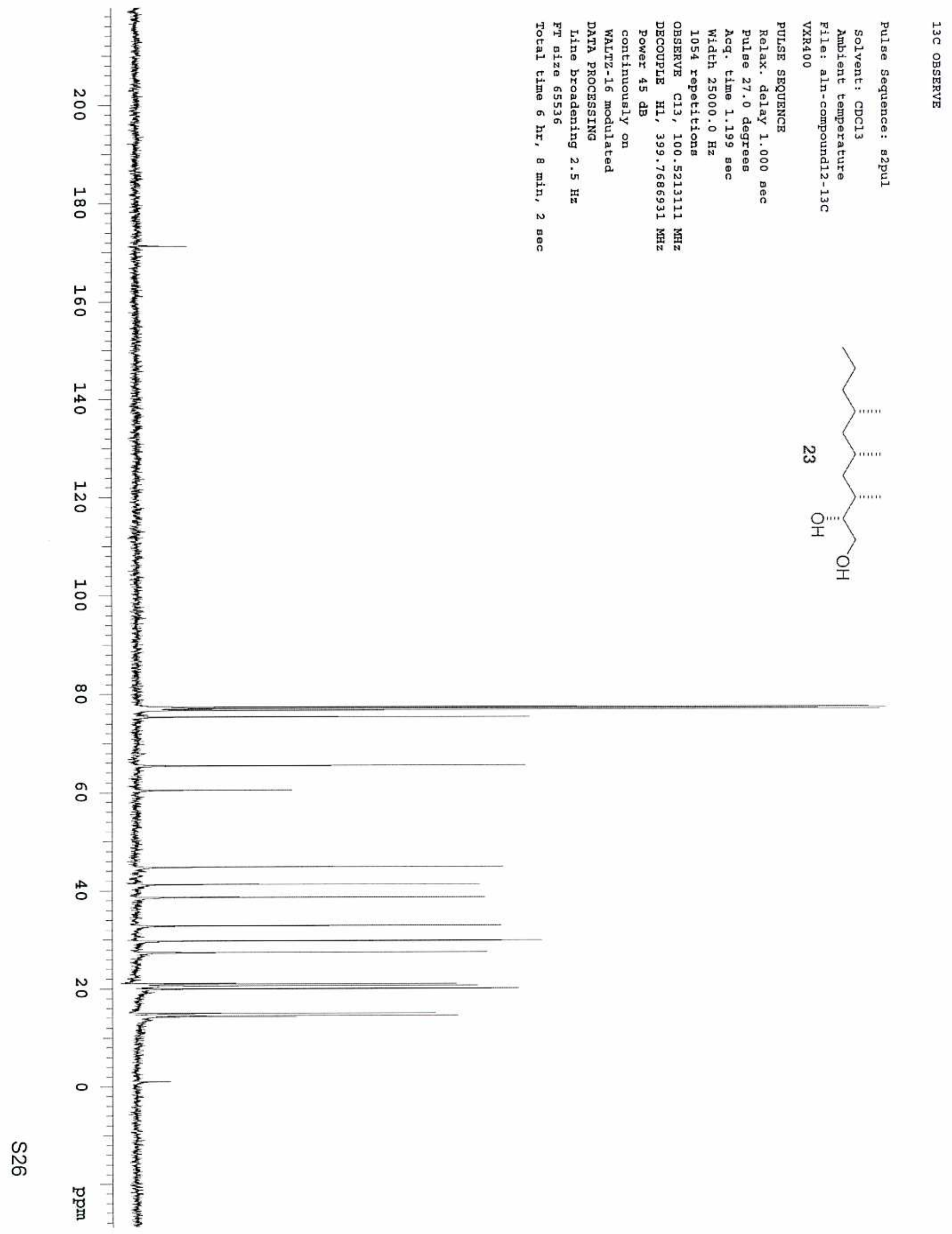




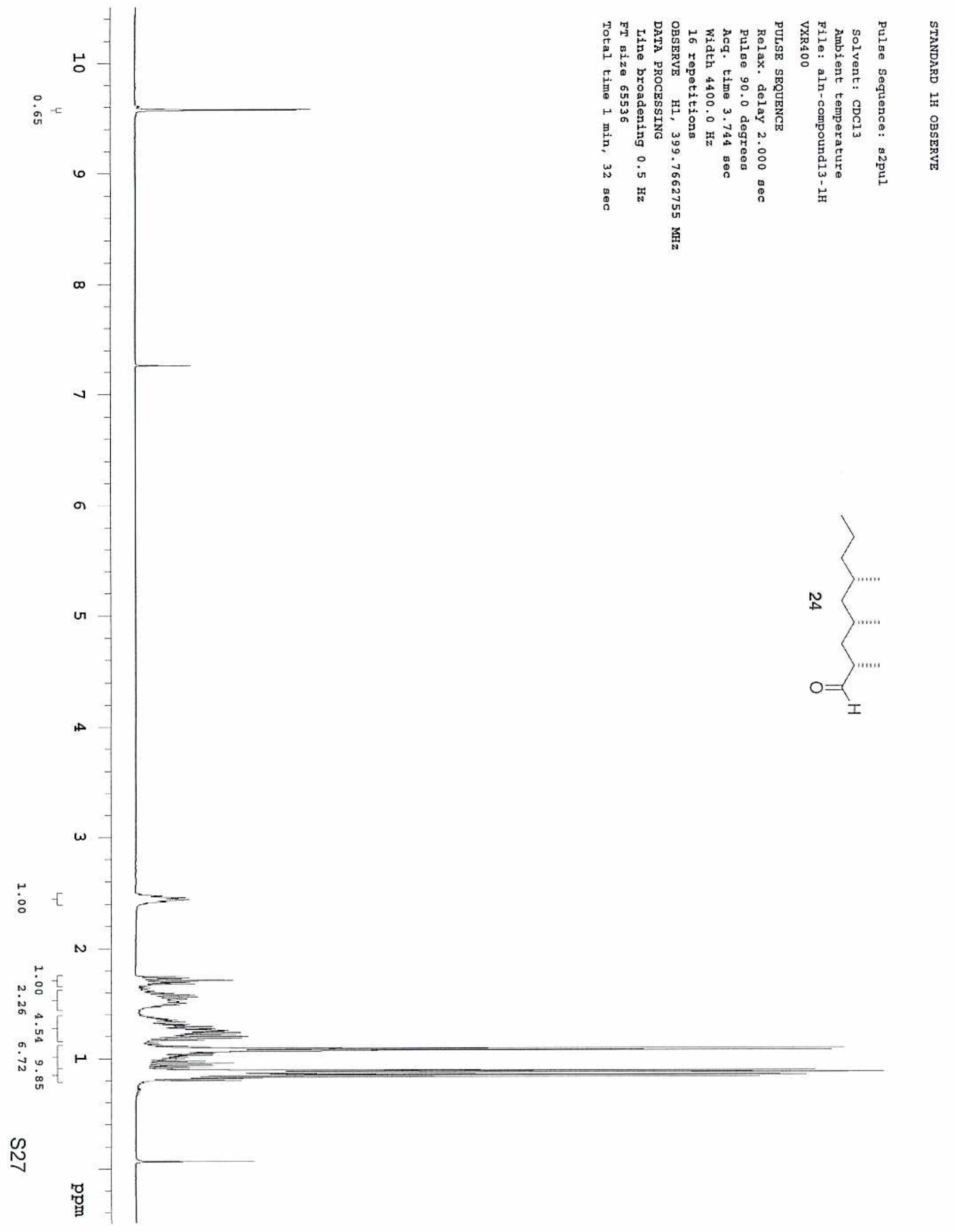




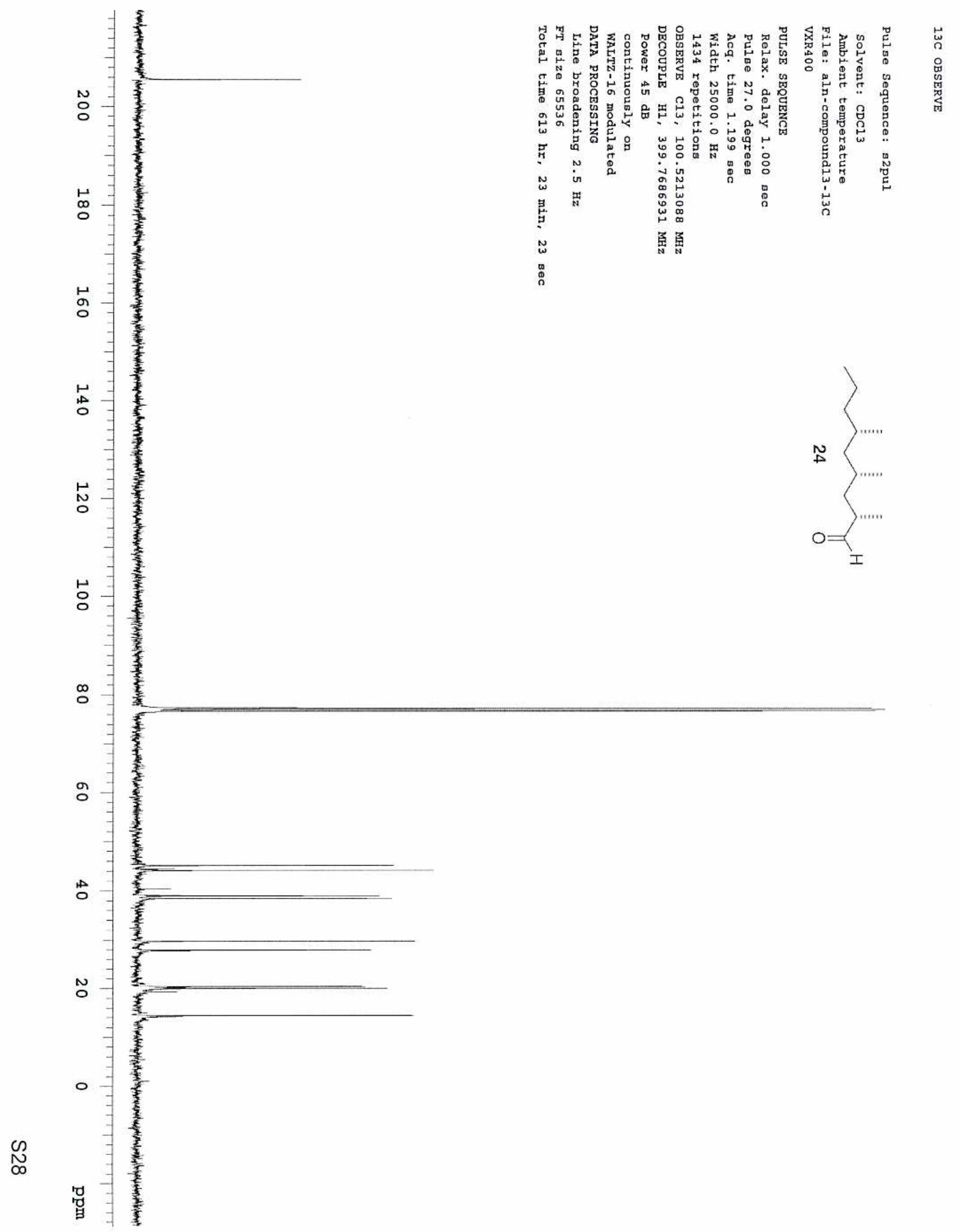




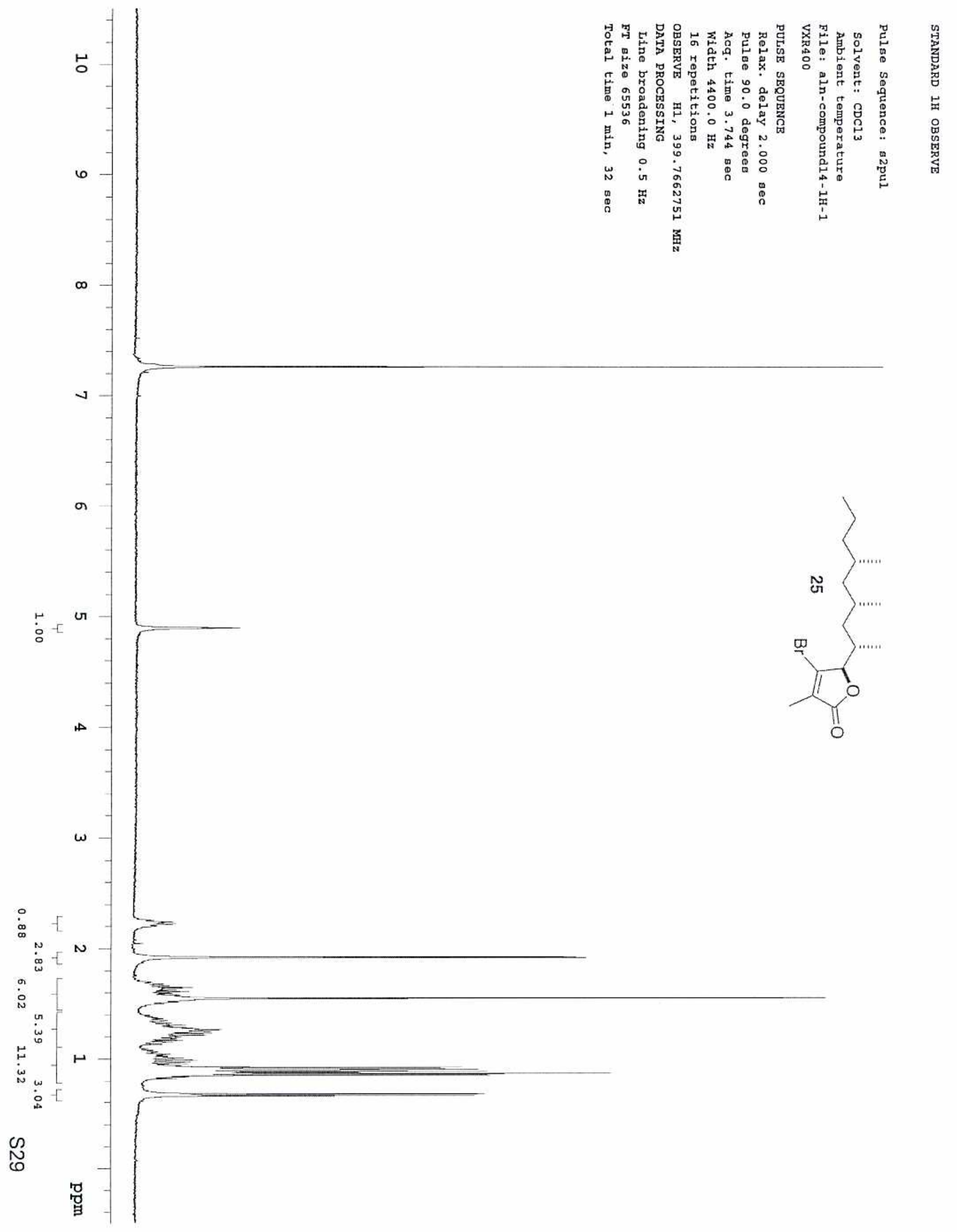




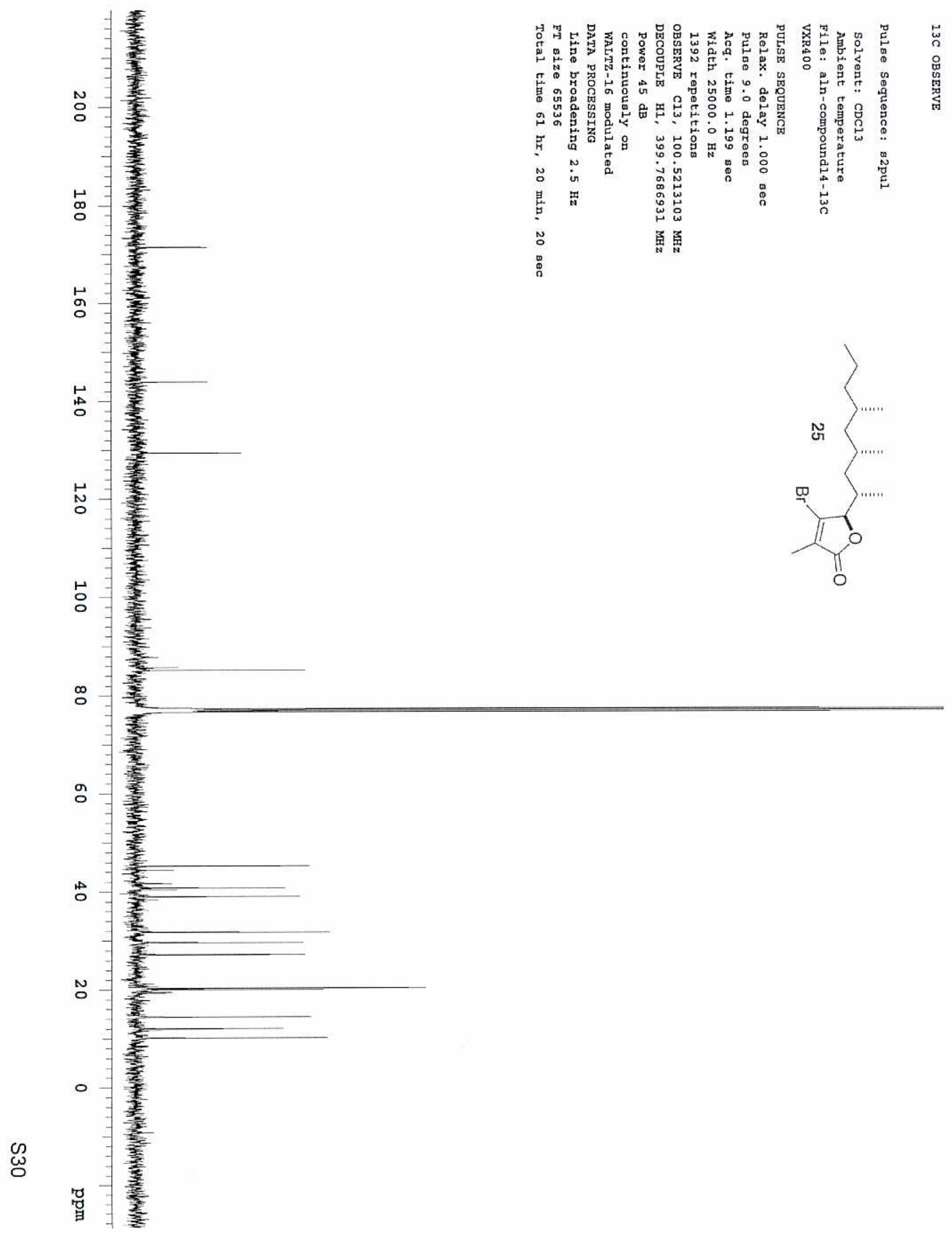




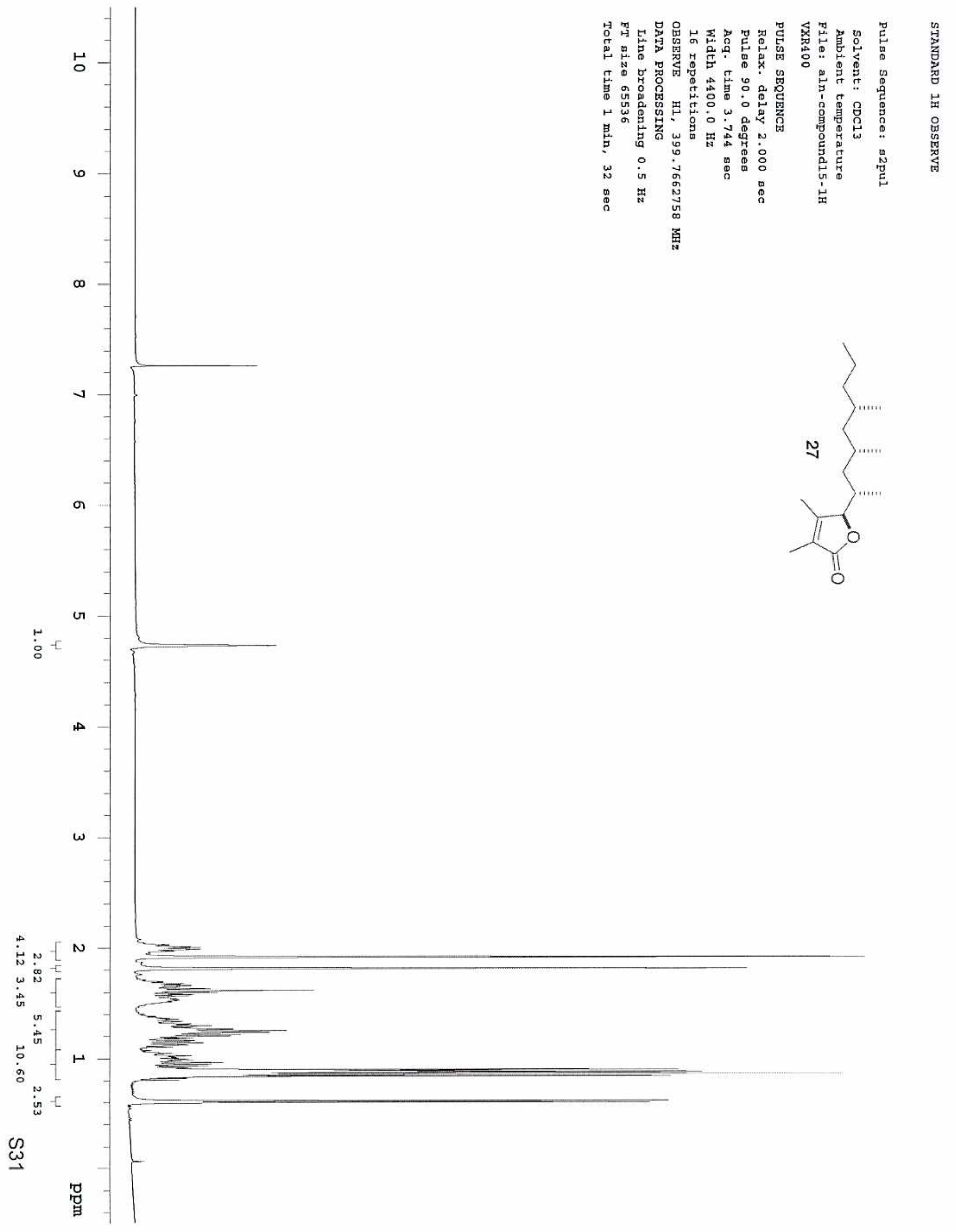




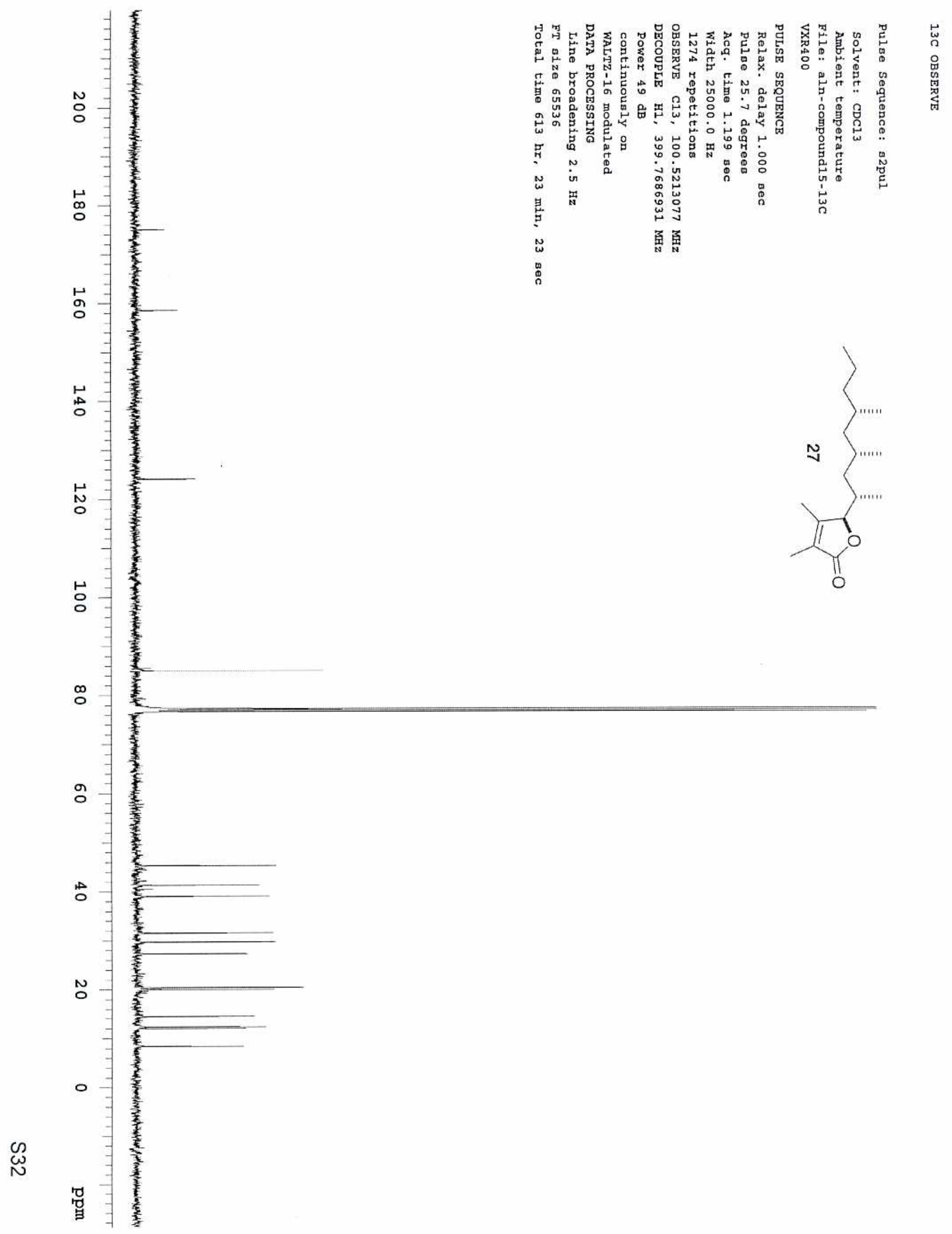




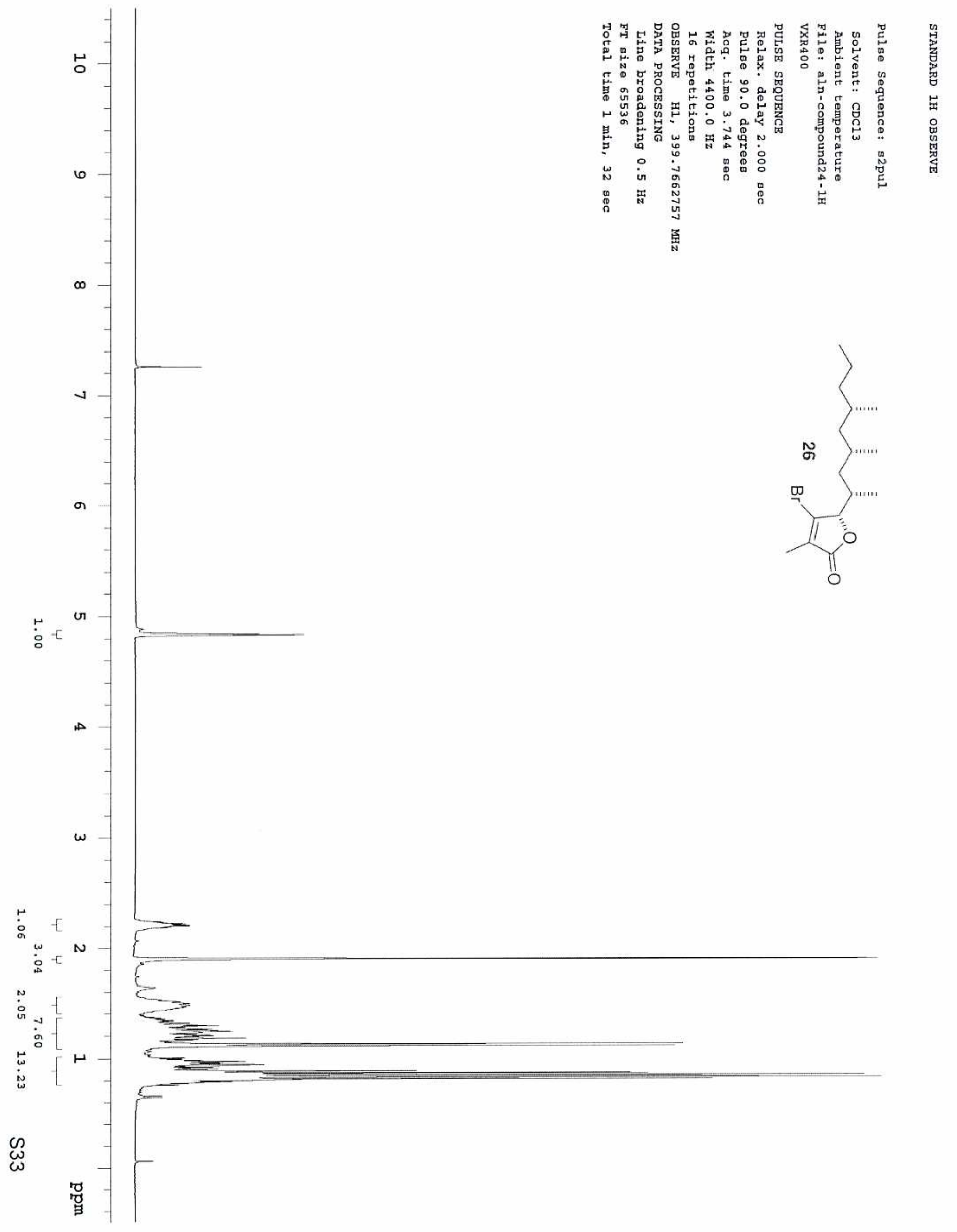




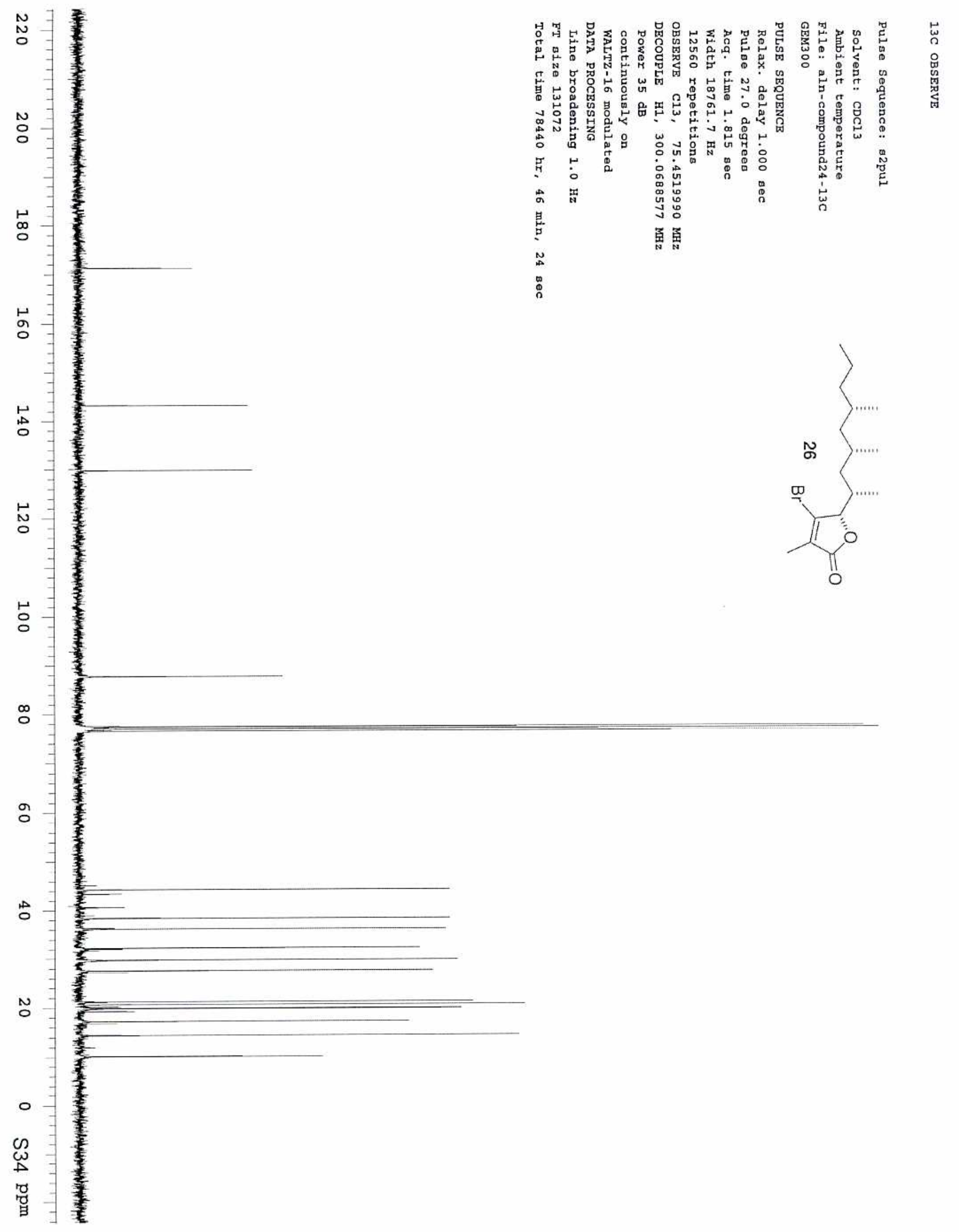




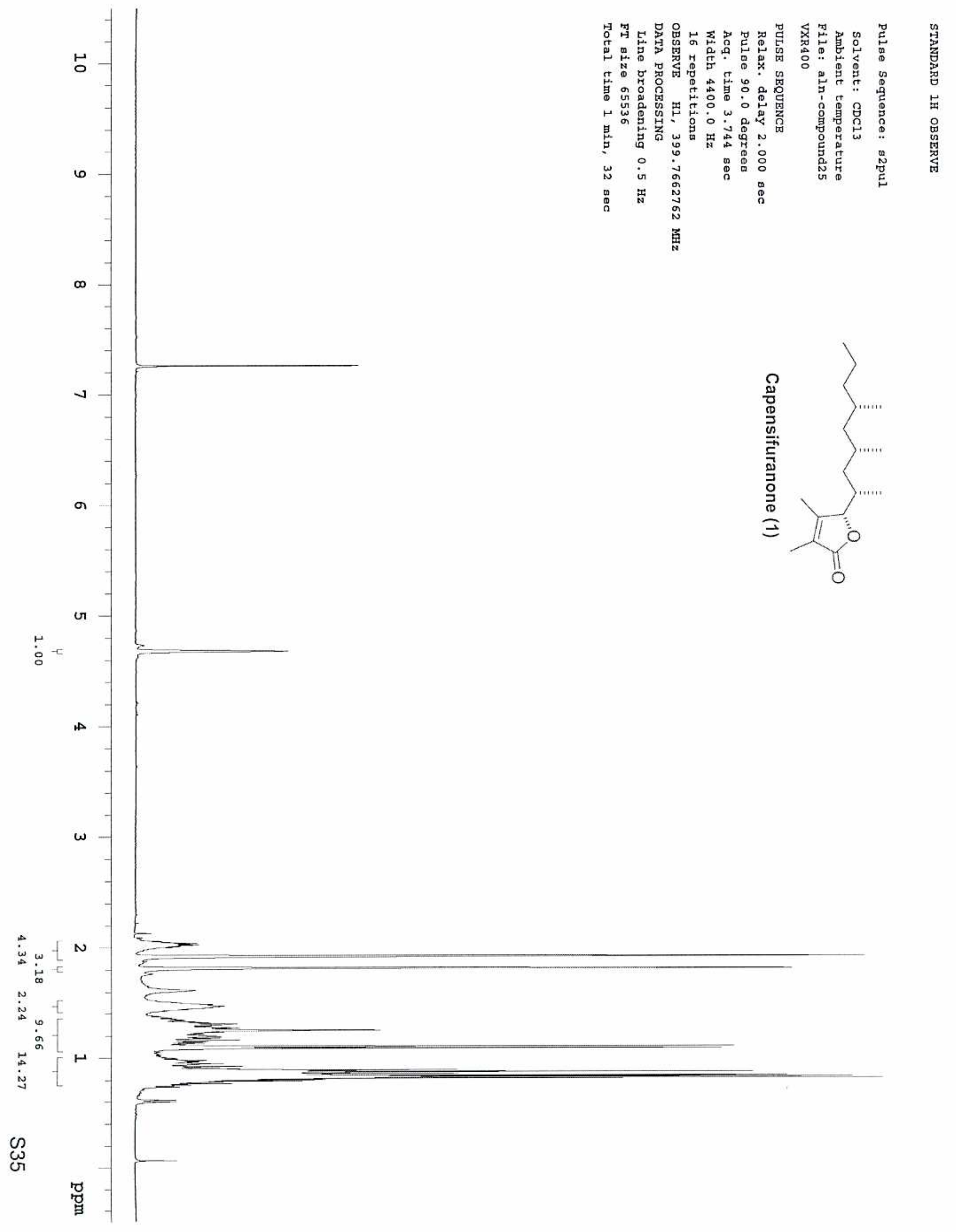




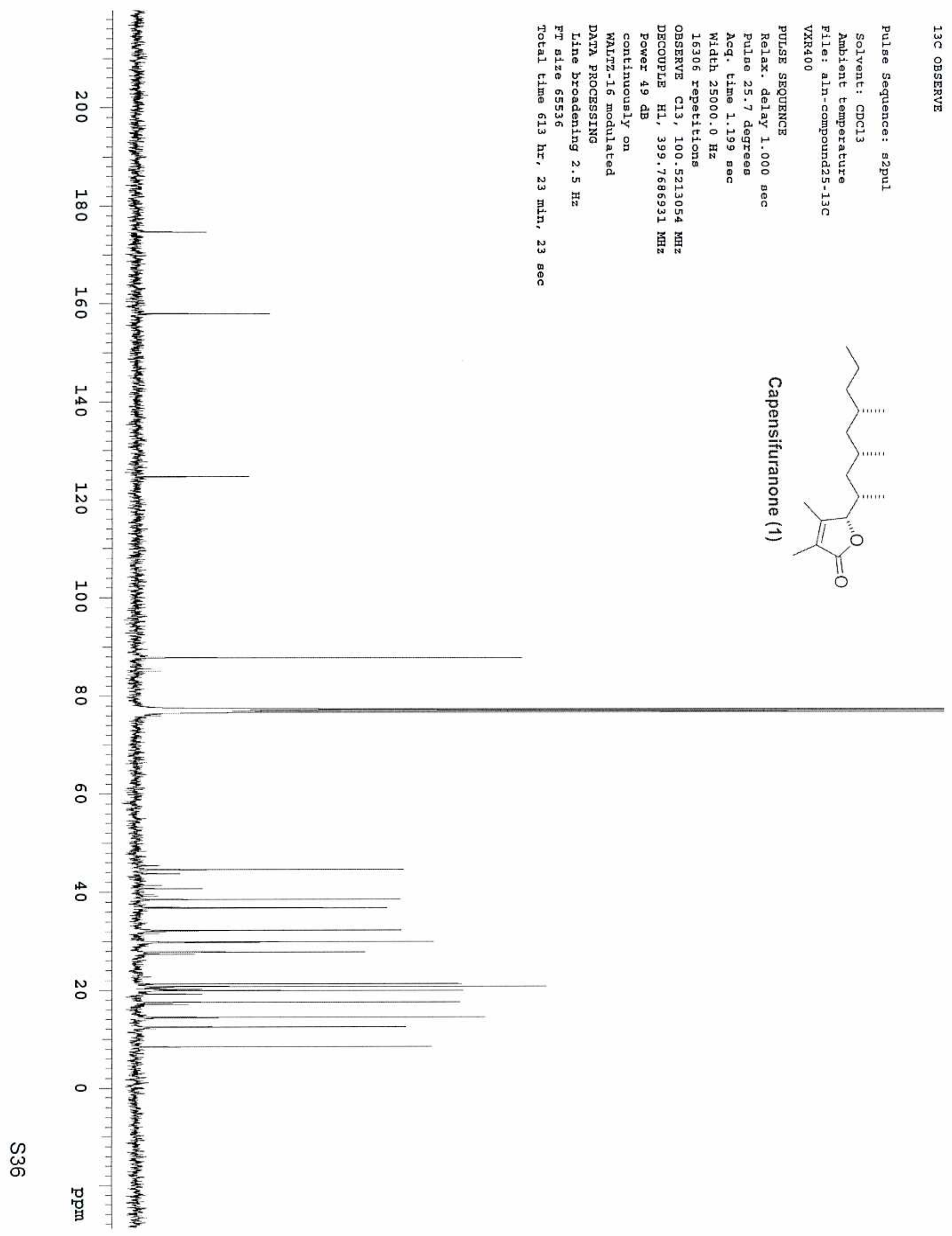

